\title{
Exploring brain functions in autism spectrum disorder: a systematic review on functional near-infrared spectroscopy (fNIRS) studies
}

Fen Zhang, Herbert Roeyers

Department of Experimental Clinical and Health Psychology, Ghent University, Henri Dunantlaan 2, 9000 Ghent, Belgium

Fen Zhang, +32 465532858, Fen.Zhang@Ugent.be , ORCID ID: 0000-0001-7135-3960 


\title{
Exploring brain functions in autism spectrum disorder: a systematic review on functional near- infrared spectroscopy (fNIRS) studies
}

\begin{abstract}
A growing body of research has investigated the functional development of the brain in autism spectrum disorder (ASD). Functional near-infrared spectroscopy (fNIRS) is increasingly being used in this respect. This method has several advantages over other functional neuroimaging techniques in studying brain functions in ASD, including portability, low cost, and availability in naturalistic settings. This article reviews thirty empirical studies, published in the past decade, that used fNIRS in individuals with ASD or in infants with a high risk of developing ASD. These studies investigated either brain activation using multiple tasks (e.g., face processing, joint attention and working memory) or functional organization under a resting-state condition in ASD. The majority of these studies reported atypical brain activation in the prefrontal cortex, inferior frontal gyrus, middle and superior temporal gyrus. Some studies revealed altered functional connectivity during resting-state, suggesting an inefficient information transfer between brain regions in ASD. Overall, the findings suggest that fNIRS is a promising tool to explore neurodevelopment in ASD from an early age.
\end{abstract}

Keywords Autism spectrum disorder, functional near-infrared spectroscopy, fNIRS, neurodevelopmental disorders, brain development

\section{Background}

Autism spectrum disorder (ASD) is a high incidence neurodevelopmental disorder. The prevalence of ASD is estimated at 6.2 per 1000 people worldwide (Elsabbagh et al., 2012), and a recent study of 8-year-olds in the United States found a prevalence as high as 16.8 per 1000 people (Centers for Disease Control and Prevention., 2014). The core symptoms of ASD include a deficit in social communication and interaction, as well as restricted/repetitive patterns of behaviour or interests (American Psychiatric Association, 2013; Maenner et al., 2014). ASD is likely a result of compounded effects of early neural development and social environment adaptation. However, the etiology of ASD has not yet been clearly identified partly due to the large degree of heterogeneity manifested in the clinical phenotype, as well as the limitations of the available technologies for measuring the underlying neural basis. Recent advances in our understanding of neuromechanisms in ASD were facilitated by rapidly developing brain imaging techniques, including functional magnetic resonance imaging (fMRI), magnetoencephalography (MEG), and electroencephalography (EEG). These techniques, however, all have their limitations (e.g. high cost, loud noises, sensitivity to movements etc.) in exploring brain development in ASD, especially in infants and young children with ASD. The emergence of functional near-infrared spectroscopy (fNIRS), as a valuable tool for detecting brain functions by measuring the changes of hemodynamic response, helps us to better understand the early development of brain functions in ASD (Gervain et al., 2011; Wilcox and Biondi, 2015).

To our knowledge, this paper is the first systematic review to discuss findings of abnormal brain activation and functional integration in ASD as revealed by fNIRS. First, we provide a brief overview of brain functional activation and connectivity in ASD, as well as a description of fNIRS together with its advantages in the exploration of ASD. Second, a comprehensive search for empirical studies in terms of the implementation of fNIRS in the field of ASD is illustrated. Finally, the remaining challenges and future research directions in this emerging field are discussed. 


\subsection{Functional brain activation and connectivity in ASD}

In the field of neurology and neuroscience, most theoretical accounts of brain functions are based on either functional localization (i.e. the activation of specific brain areas) or functional integration (i.e. the connection among different brain areas) (Friston, 2011; Sporns, 2013, 2003). The basic assumption of functional localization is that functions can be localized in one or more cortical areas. This view has been widely adopted in the studies of ASD to identify impaired brain areas by comparing brain activity between patients and typical developing controls (TDC). A bundle of socially relevant brain areas were found to be impaired to some extent in ASD, including the superior temporal sulcus (STS), amygdala, inferior frontal gyrus (IFG) and temporo-parietal junction (TPJ) (Pelphrey et al., 2012; Philip et al., 2012). These brain regions are supposed to be associated with various functions including social perception, joint attention, mentalizing, language, as well as executive functions necessary for cognitive control.

Although the brain function positioning helps us to localize particular brain regions with specific functions, it has become apparent that brain regions do not operate independently even for completing a simple task. Recently, functional integration among brain regions that are spatially separated but share similar functions has been recognized (Kana et al., 2014; Sporns, 2013). One approach to characterize functional integration is to assess the synchronization of neural activity among brain areas, also known as functional connectivity. The majority of fMRI studies in ASD suggests that individuals with autism show a pattern of altered functional connectivity among structurally separated brain regions (Abrams et al., 2013; Itahashi et al., 2015; Keown et al., 2013). An under-connectivity was observed in autism between the frontal gyrus and posterior regions involved in "theory of mind (ToM)" - the social ability of attributing mental states to oneself or others'(Baron-Cohen, 2001; Kana et al., 2009; Paynter et al., 2016), the left hemispheric posterior superior temporal gyrus (pSTG) and the dopaminergic reward areas (Abrams et al., 2013), as well as the insula and the amygdala involved in emotion processing (Ebisch et al., 2011). This decreased functional connectivity in ASD suggests that the transmission of neural information in the brain of individuals with ASD is proceeding in a less efficient manner compared to typical controls. However, current findings based on previous neuroimaging studies do not allow us to draw a clear conclusion on the brain functions in ASD. In order to better understand the changes of the different pattern of brain functions in ASD, multiple technologies and methodologies are needed to further explore these two important issues from different perspectives.

\section{2 fNIRS and its advantages in ASD research}

fNIRS is a non-invasive neuroimaging instrument which measures brain activity by using near-infrared (NIR) spectrum light. The 650-900 nm NIR light is strongly absorbed by oxyhemoglobin (oxy-Hb) and deoxyhemoglobin (deoxy$\mathrm{Hb}$ ). Since the light in this spectrum is relatively transparent to human tissues, the fluctuation of hemoglobin concentration can be detected through the use of light attenuation at multiple wavelengths (Ferrari and Quaresima, 2012). One important physiological principle underlying fNIRS is the neuro-vascular coupling through which there is a relationship between neuronal activity and changes in localized cerebral blood flow (CBF). Both fNIRS and fMRI depend on this coupling, also known as the hemodynamic response or Blood-Oxygenation-Level-Dependent (BOLD) response, to probe the neural activity (Raichle and Mintun, 2006). There are three common fNIRS techniques based on this neuro-metabolism, including continuous wave (CW), frequency-resolved and time-resolved NIRS (see Gervain et al., (2011) for more details). The CW system is currently the most widely used technique. It measures the neural activity by monitoring changes in light attenuation, which is proportional to the concentration changes of tissue chromophores (e.g. oxy-Hb and deoxy-Hb), based on 
measurements of continuous-wave NIRS light at two or more wavelengths. Given that the light is either absorbed by the chromophores, transmitted to the detector, or scattered when it travels through the brain, the modified Beer-Lambert law is applied to calculate the concentration of the oxy-Hb and deoxy-Hb (Baker et al., 2014; Gervain et al., 2011). Based on these physical and physiological principles, fNIRS allows us to measure the neural response through changes in hemoglobin concentration detected by the NIR light.

fNIRS has several advantages over other neuroimaging techniques, such as portability, low cost, and usefulness in naturalistic settings. Among neuroimaging technologies, it has a better temporal resolution compared to fMRI, and a higher spatial resolution than EEG. In addition to these general advantages, fNIRS has distinct superiorities in studying brain functions of ASD. First, with the introduction of fNIRS, developmental researchers can have a deeper insight into the functional activation and organization of the brain in infants and young children, which is hard to realize with fMRI especially when they are awake or hyperactive (Siddiqui et al., 2017). Recent reviews on the usability of fNIRS in infant populations (Gervain, 2014; Gervain et al., 2011; Lloyd-Fox et al., 2010; Wilcox and Biondi, 2015) suggest that the benefits of fNIRS make it an effective option for the study of infants at high risk of developing ASD (HR), who have an older sibling with ASD and are as such more likely to develop ASD compared to children without a family history of developmental disorders. Taking into account the valuable physiological information provided by HR infants, studies of HR infants have the potential to clarify early manifestations of functional and structural features of the ASD brain (Bölte et al., 2013; Sandin et al., 2014) (further discussion in 4.3.1). Second, fNIRS has proven suitable for studying patients with psychiatric disorders (Ernst et al., 2012), including schizophrenia and developmental disorders such as attention-deficit/hyperactivity disorder (ADHD) and also ASD (Iwanaga et al., 2013; Zhu et al., 2014). For those who suffer from a developmental disorder, it is a challenge to participate in an fMRI study because some of them can hardly control their hyperkinetic behaviour or endure the enclosed space and loud noises. Compared to the limited and claustrophobic space in fMRI research, the bigger visible room and the attenuated noise in fNIRS lets participants experience more natural conditions during experiments. The reduced noise surrounding (compared to fMRI) also makes fNIRS a good technique to investigate language perception, which is essential for adequate social communication and often impaired in ASD. It should however be noted that there are also some limitations when using fNIRS. The spatial resolution of fNIRS, for example, is inferior to that of fMRI and it measures the hemodynamic response mainly from the surface of the scalp (Lloyd-Fox et al., 2010). But taken together, the advantages of fNIRS outweigh its disadvantages in the investigation of brain functions in people with ASD (Wilcox and Biondi, 2015), and hence fNIRS is considered as a promising tool to explore neurodevelopment of ASD from an early stage.

\section{Methods}

\section{$2.1 \quad$ Literature search}

We conducted a comprehensive search for empirical studies that used fNIRS in individuals with ASD or in HR infants. Publication year was not restricted, and the latest database search was performed in January of 2018. The online search was performed in MEDLINE via PubMed interface, Scopus, and ISI Web of Science. Within each database, the following broad keywords were used: terms related to ASD (i.e. autism or Asperger or pervasive development disorder or autism spectrum disorder or ASD), and a combination of terms for fNIRS (i.e., near-infrared spectroscopy or NIRS). All terms in each category were included within parentheses using the Boolean operator "OR", and the resulting two brackets were connected by “AND”. 


\subsection{Inclusion criteria}

After removing duplicate records, the articles produced by the search were required to meet pre-established criteria as to confirm the studies were relevant to the field of ASD and fNIRS. The inclusion and exclusion criteria were defined as follows:

- Articles were required to be published in English.

- $\quad$ Articles were required to be a peer-reviewed research (not a conference abstract/paper).

- Articles were required to be empirical research in which a fNIRS experiment was conducted (not a review/summary article) in ASD or HR infants.

- Studies were excluded if the participants did not have a diagnosis of ASD or were not at high risk for ASD, but were only reported to show traits of autism.

\subsection{Assessment of risk of bias}

We have assessed study quality through the Cochrane Risk of Bias Tool (CRBT; Higgins and Green, 2011). In this review, four types of biases have been evaluated: detection, attrition, reporting and other sources of bias. The evaluation of the sequence generation and the allocation concealment provided by CRBT was inapplicable for this review study, as most of the included studies used a blocked randomization design in which the allocation of participants was known after recruitment. The bias assessment caused by blocked randomization has been incorporated in the assessment of other sources of bias.

\subsection{Data extraction and synthesis}

Crucial information has been extracted from all the studies selected, such as average age and diagnostic/screening criteria for the ASD and HR groups, gender ratio and sample sizes of the TDC groups as well as the ASD and HR groups, and information on the experimental tasks used during fNIRS measurements. The studies we have searched were first classified into two chief categories: functional activation and functional connectivity. The studies examining cortical activation during various tasks have been sub-grouped into three categories: social perception and integration (e.g. facial processing, joint attention, and theory of mind), language (e.g. speech processing), working memory and inhibition (e.g. letter fluency, tasks switching, and inhibition). Details of NIRS measurements were recorded as well, including NIRS systems, number of channels and source-detector distance.

The limited number of studies in each category and the inconsistencies of the NIRS measurements used across different laboratories have permitted us to provide merely a descriptive synthesis on the basis of the overall results. To better understand the cortical activation and functional connectivity in individuals diagnosed with ASD examined by fNIRS, findings showing significant differences between ASD groups and control groups were extracted.

\section{Results}

\subsection{Overview of included papers}

Thirty articles specifically using fNIRS to study individuals with ASD or HR infants were identified. The search of multiple databases yielded 312 papers in total. After omitting duplicates, 176 of them were selected for the follow-up screening process (see Fig. 1). Based on inspections of abstracts and titles, a total of 141 studies that did not meet the inclusion criteria were excluded, most of them were unrelated to both ASD and fNIRS ( $n=123$ ) or belonged to a review/book chapter/conference abstract $(n=18)$. The remaining 35 papers were evaluated based on the full text. Finally, another five articles were excluded as they were conference papers $(n=2)$, in abstract format $(n=1)$, or performed eye-tracing/genetic 
measurement together with fNIRS data presented elsewhere $(n=2)$. Both authors have evaluated these articles and have agreed on the selection.

Based on our search, the first study concerning ASD brain functions using fNIRS was published in 2006 (Kuwabara et al., 2006). Whereas there were only 4 publications before 2011 ( $n=1$ in 2006, $n=1$ in 2007, $n=2$ in 2009), the number of publications since 2011 varies between 2 and 6 per year. We noticed a slight growth in the number of publications in this research field over the years, although there are still not enough studies for this increase to be statistically significant. Each of the included studies was summarized in Table 1 and Table 2 in terms of (a) first author and year of publication; (b) type of task; (c) participant characteristics (e.g. age, sample size and diagnosis criteria); (d) NIRS system (wavelength, pre-defined channels and source-detector separations); and (e) main findings. The risk of bias for the included studies is summarized in Supplementary Fig.1. Twelve studies met at least four of the criteria (judged as "low-risk"), and eight studies met three of the criteria. The commonest unclear bias we have faced was due to blocked randomization, which increases the bias for predicting subject assignment.

\subsection{Characteristics of participants}

In total, 429 participants with ASD or at high risk of ASD have been reported on, although there was overlap between studies. The largest sample size contained 33 participants at high risk of ASD, whereas the smallest sample reported only on one participant with pervasive development disorder (PDD) in a study of epilepsy. Across all 28 studies that reported gender ratio ( $n=2$ did not report gender), 67.9\% ( $n=256)$ of the participants were male and $32.1 \%(n=121)$ were female. Seven studies only included male participants. With respect to age, $53.3 \%(n=16)$ of the studies involved participants with a mean age ranging from 12 months to 18 years old, whereas the proportion of studies of infants $(n=6$, mean age $<12$ months) and adults ( $n=7$, mean age $>18$ years) accounted for $20 \%$ and $23.3 \%$ of the studies respectively. The remaining study $(n=1)$ involved both a child and an adult group.

Clinical diagnosis of ASD was generally based on the DSM-IV ( $n=18$ studies) and DSM-5 ( $n=2$ studies) criteria, and infants were defined as high-risk when they had at least one older sibling with ASD ( $n=6$ studies). Eleven studies specified the diagnosis of their participants based on DSM-IV: 73 participants had been diagnosed with autism (mainly 'highfunctioning autism'), $53 \mathrm{had}$ an Asperger Syndrome diagnosis, 28 had a PDD-NOS diagnosis and one participant was diagnosed as having atypical autism. Within those studies using DSM-IV criteria, a total of 95 participants ( $n=4$ studies) were described as diagnosed with ASD without specifying the diagnosis and 31 participants ( $n=3$ studies) were described as having PDD. A total of 118 high-risk infants were investigated in six studies. In addition, sixteen studies specified the diagnostic instruments used to assess the clinical performance, such as the Autism Diagnostic Observation Schedule (ADOS), the Autism Diagnostic Interview-Revised (ADI-R) and other diagnostic instruments (see Table 1 and Table 2 for details).

\subsection{NIRS measurement}

A total of 14 NIRS systems have been applied to explore brain function in individuals with ASD. The details of NIRS measurement have been listed in Table 1 and Table 2. The most commonly used system (in nine studies) is the Hitachi ETG-4000 system with light sources emitting NIR light at 695 and $830 \mathrm{~nm}$. This system sets the distance between source and detector at $3 \mathrm{~cm}$. Across the different NIRS systems, two (e.g. Hitachi ETG-4000) or three (e.g. Shimadzu's, FOIRE-3000) wavelengths ranging from 690 to $850 \mathrm{~nm}$ were used to measure hemoglobin changes. Most NIRS systems (in twenty-five studies) used source-detector distances at $3 \mathrm{~cm}$, whereas the UCL Optical Brain Imaging System (in three studies), the 
Huazhong University JH-NIRS-BR-05 system (in one study) and the TechEn, CW6 system (in one study) used distances of 2 $\mathrm{cm}, 2.2 \mathrm{~cm}$, and $2.6 \mathrm{~cm}$ respectively. The number of measured channels, commonly consisting of a pair of sources and detectors, varied throughout studies. The minimum number of channels used was 2 (in six studies) and the maximum number was 69 (in one study).

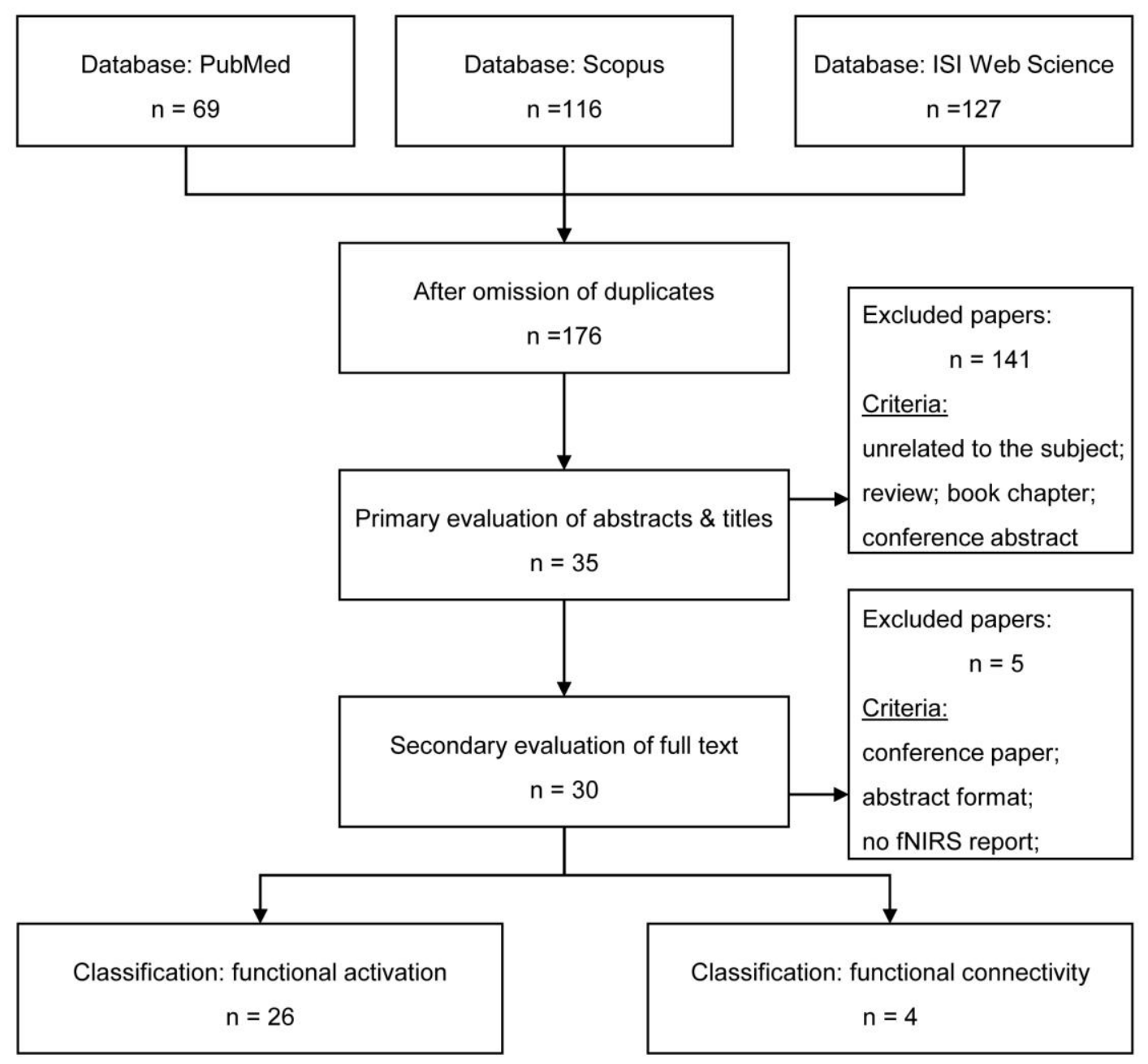

Fig. 1 Flow diagram of the literature search and subsequent screening performed in this the review

\subsection{Brain functions in ASD}

Of the 30 studies targeting brain responses in ASD, 26 studies focused on brain activity under a specific experimental setting, and another 4 studies emphasized functional connectivity between brain regions. Of the 30 studies, thirteen studies (43.3\%) mainly reported on the prefrontal cortex (PFC), seven studies (23.3\%) focused on the temporal cortex, two studies (6.7\%) examined the frontal cortex, and another eight studies (26.7\%) involved a wide range of brain regions. Here, one study involving a letter-fluency task (Gallagher et al., 2007) was classified as "language", as it was 
designed to examine language processing and covered brain regions associated with language. We retained the terms of the "frontal" and "prefrontal" cortex after extracting from studies.

\subsubsection{Brain functional activation}

Fourteen of the studies concerning brain activity involved social processing and integration ( $n=3$ for social perception, $n=7$ for facial processing, $n=4$ for joint attention and theory of mind), three involved language and nine involved working memory and inhibition ( $n=3$ for response inhibition, $\mathrm{n}=3$ for working memory and $n=3$ for letter fluency). The tasks used as well as the main findings of the papers that investigated brain activation in individuals with ASD are listed in Table 1.

\section{Social perception and interaction}

Three fNIRS studies concerning social perception found that HR infants aged 4 to 6 months showed weaker activation in response to visual and auditory social stimuli in the temporal cortex compared to low risk (LR) controls, predominantly in the left STS (Lloyd-Fox et al., 2013, 2017) and the right posterior temporal cortex (Braukmann et al., 2017).

Seven fNIRS studies focused on facial processing in individuals with ASD and found a decreased response in individuals with ASD compared to individuals with TDC in the IFG during self-face recognition (Kita et al., 2011) and imitation of emotional facial expressions (Mori et al., 2015), as well as in the PFC when processing fearful faces (Nakadoi et al., 2012). A different type of activation response with smaller oxy-Hb and greater deoxy-Hb changes was also found in the frontal and lateral regions in 5 to 7-month-old HR infants as compared to LR infants during familiar and non-familiar face perception (Fox et al., 2013). By applying a support vector machine (SVM) that builds a binary classifier to assign individuals into different groups, Ichikawa and colleagues (2014) classified children aged around 9 years old into an ASD group and an ADHD group based on the hemodynamic response to their mother's face. Classification accuracy reached $84 \%$ for the best subset of channels and $62 \%$ for all channels.

With regard to social-cognitive tasks, including joint attention, mindreading and imitation, the results of fNIRS studies showed abnormal activity patterns in children with ASD in the frontal cortex, mainly in the IFG and PFC (Chaudhary et al., 2011; Zhu et al., 2015). Compared to the TDC, lower activation was reported in children with ASD in the PFC when following eye gazes of others (Zhu et al., 2015) and describing the mental state of a person (Iwanaga et al., 2013), as well as reduced activation in the IFG and decreased left lateralization in the rostral PFC for imitation tasks (Tamura et al., 2012).

\section{Language}

One study reported weaker functional lateralization for speech in children with ASD compared to a control group (Minagawa-Kawai et al., 2009), while another study found significant lateralization for speech in the Broca's area in one child with PDD (Gallagher et al., 2007). Regarding early language development, decreased activation was found in a LR female group at 3 months of age during a syllable repetition task whereas no such change was observed in a HR female group (Edwards et al., 2017).

\section{Working memory and inhibition}

Nine fNIRS studies have investigated working memory and inhibition in ASD. These studies observed an atypical activation in the PFC during letter-fluency tasks (Iwanami et al., 2011, 2010; Kawakubo et al., 2009), working memory tasks (Narita, 2015; Yanagisawa et al., 2016) and task switching/inhibition (Funabiki et al., 2012a, 2012b; Narita et al., 2012). Studies of working memory conversion showed that a switching tendency of hemodynamic activation in the PFC was obvious in TDC but was not shown instantly in ASD (Narita et al., 2012; Yanagisawa et al., 2016). Regarding inhibitory 
control ability in ASD, studies showed reduced activation in the right PFC during a Go/No-go task (Funabiki et al., 2012; Xiao et al., 2012) compared to a TDC group and in the left ventrolateral PFC during a stop signal task compared to an ADHD group (Ishii-Takahashi et al., 2014). During letter fluency tasks, researchers found a decreased oxy-Hb response in the PFC in ASD as compared to TDC (Iwanami et al., 2011, 2010; Kawakubo et al., 2009), as well as an association between this reduction in oxy-Hb and the verbal communication deficits in the ASD group (Kawakubo et al., 2009).

\subsubsection{Brain functional connectivity}

The main findings of fNIRS studies with regard to functional connectivity in individuals with ASD are listed in Table 2. Only one of the four studies was stimulation-free, while the other three were conducted with language stimuli, a TV show or a cartoon. As shown in Table 2, decreased functional connectivity between anterior and posterior brain regions was found in HR infants at 3-12 months (Keehn et al., 2013). The weaker RSFC has also been reported (a) between bilateral temporal lobes ( $\mathrm{Li}$ et al., 2016) and (b) within the right PFC ( $\mathrm{Li}$ and $\mathrm{Yu}, 2016$ ) in children with ASD. Only one study reported increased functional connectivity in the bilateral anterior PFC, which was positively correlated to the severity of the social deficit, in 3-7 years old children with ASD (Kikuchi et al., 2013). By using functional network efficiency to discriminate ASD from TDC, $\mathrm{Li}$ and Yu (2016) reported a classification accuracy rate of $83.3 \%$ while Li et al., (2016) reported a sensitivity of $81.6 \%$ and a specificity of $94.6 \%$.

\section{Discussion}

After a comprehensive search, 30 articles related to the brain functions of people with or at risk for ASD using fNIRS were identified. The experimental tasks used in the included articles were designed to investigate the various aspects of ASD characteristics and included a wide range of social tasks (e.g., facial processing, joint attention, and theory of mind), language tasks (e.g., speech processing), as well as other cognitive tasks (e.g., working memory, switching and inhibition). Only a few studies focused on the functional connectivity between brain regions. We further discuss these aspects below and highlight some of the challenges and research tendencies in this field.

\subsection{Methodology of included literature}

\subsubsection{Study participants}

Although the diagnostic criteria used (e.g. DSM-IV and DSM-5) had been depicted in the majority of fNIRS studies in ASD, there are still some studies that did not clearly describe the specific diagnostic tools used (e.g. ADOS and ADI-R). Referring to the gender ratio, the overall ratio of male to female participants in fNIRS studies of ASD is over 2:1, which is quite typical in ASD research, as the gender ratio of individuals with ASD is close to 3:1 (Loomes et al., 2017). However, there are still some studies that only include male participants. In addition, the sample sizes of the different fNIRS studies in ASD are relative small, which may contribute to low statistical power and reduce the reliability of the research. Recruitment of larger samples and a detailed description of clinical diagnoses should be encouraged in future fNIRS studies in the field of ASD.

A general tendency in fNIRS literature pertaining to ASD is to investigate the early brain functions in children and infants. This happens to be the opposite of fMRI research in the field of ASD, which favors mapping the adult's brain (Philip et al., 2012). Using fNIRS to explore individuals with ASD during early childhood might compensate for the lack of understanding of early brain development in ASD (see also 4.3.1).

\subsubsection{NIRS systems and measurements}


A noteworthy issue concerning fNIRS studies in ASD is that the NIRS systems and the optodes placements vary throughout the particular laboratories. Most of these NIRS systems used continuous wave NIR light to monitor the changes of hemoglobin concentration. However, the light's wavelengths, which may contribute to the quality of signals (Gervain et al., 2011), across these NIRS systems are not always consistent. The source-detector separation, an important parameter of a NIRS system for determining the depth of penetration, also showed slight differences among the fNIRS studies in ASD. The number of channels employed, directly affecting the scope of covered brain region, ranged from very few channels to nearly a hundred channels. Although parameters were carefully chosen for each study, these differences make it more difficult to compare and standardize various studies.

\subsection{Brain functions in ASD}

\subsubsection{Brain functional activation}

As shown above, advancements in optical imaging techniques allow us to explore the brain activation in ASD in a variety of experimental settings. Converging evidence from the fNIRS studies further support the notion that atypical brain activation under specific tasks is related to behavioural symptoms in individuals diagnosed with or at risk for ASD.

\section{Social perception and interaction}

In the past decade, the notion of a "social brain" in ASD has come up, together with the unsolved questions of brain development in high-risk infants (Elsabbagh and Johnson, 2016). fNIRS studies provide more evidence for an altered development of the "social brain" in ASD. For instance, lower activation in the temporal and frontal cortices in infants at high risk is observed with fNIRS in the context of social perception (Braukmann et al., 2017; Fox et al., 2013; Lloyd-Fox et al., 2017, 2013), which has been examined less in previous neuroimaging studies and could help us to further understand early brain functioning in ASD. The negative correlation between ASD symptoms at 3 years and neural activation to social stimuli at 4-6 months (Lloyd-Fox et al. (2017) suggests that a lack of cortical specialization to external social input, mainly reported in the temporal cortex, is likely to have already existed in the first year of life in infants who later develop as ASD.

Facial processing, which is generally right hemisphere dominant in the typically developing population, is often impaired in ASD (Jung et al., 2016; Kita et al., 2011). This is supported by studies using fNIRS (Jung et al., 2016), which indicates that both hemispheres participate in face processing more equally in ASD and that their efficiency is lower than in TDC. Likewise, atypical functional activity for face processing was found to arise in the early ASD brain (Fox et al., 2013). These findings extend previous fMRI results (Harms et al., 2010; Monk, 2010) by revealing impaired functions in the frontal and prefrontal cortex in ASD when processing face information. In addition, fNIRS studies also provided more evidence for abnormal brain functions in social interaction, including imitation, joint attention and theory of mind (Chaudhary et al., 2011; Zhu et al., 2015).

\section{Language processing}

Similar to previous fMRI findings involving language in ASD (Knaus et al., 2010; Knaus et al., 2008; Verly et al., 2014), fNIRS studies indicated a distinctive pattern of activation or lateralization in the temporal and frontal cortex in individuals with ASD (Edwards et al., 2017; Minagawa-Kawai et al., 2009). Minagawa-Kawai et al., (2009) and Edwards et al., (2017) reported a weaker response to language stimuli in children with ASD and HR infants, while Gallagher et al., (2007) found a clear activation in Broca's area in a 12-year-old child with ASD. Given the very limited number of participants 
reported in the latter study, this finding should be approached with caution. In general, research on neural mechanisms of language processing using fNIRS is still relatively scarce.

\section{Working memory and inhibition}

fNIRS studies that investigated working memory and inhibition indicated an atypical activation in the PFC in individuals with ASD. These distinct patterns of neural activation during executive tasks can inform us about the engagement of cognitive control of behaviour in ASD (Corbett et al., 2010; Narita et al., 2012). For instance, Yanagisawa et al., (2016) found lower and delayed weighted separability (WS) values - indexes of quantitative evaluation that evaluate brain activity based on the feature phase of oxy-hemoglobin and its differential value - in the left dorsolateral PFC in ASD compared to TDC participants.

Response inhibition is another important executive function that involves the cognitive ability of self-suppression of task-irrelevant impulses and behaviour. Evidence of inhibitory dysfunction in individuals with ASD was found in fNIRS studies with reduced activation in the right PFC during a Go/No-go task (Xiao et al., 2012) and an auditory attention task (Funabiki et al., 2012a). These findings suggest that the difficulty of response inhibition in individuals with ASD may be related to their repetitive and stereotyped behavior, which needs to be replicated in future research.

\subsubsection{Brain functional connectivity}

The findings of the fNIRS studies further confirm that atypical behaviour in ASD is not only linked to the atypical activation patterns of specific brain regions but also associated with the disturbed collaboration between different brain regions (e.g., frontal-posterior under-connectivity) (Keehn et al., 2013; Li et al., 2016; Maximo et al., 2014; Zhu et al., 2014). Functional connectivity, which was originally measured with fMRI, has emerged as a promising method for mapping the intrinsically functional networks in the brain and has gained popularity in recent fNIRS studies. Decreased functional connectivity was observed in both children with ASD (Li et al., 2016; Li and Yu, 2016; Zhu et al., 2014) and infants at high risk of ASD (Keehn et al., 2013). These findings of atypical functional connectivity represent inefficient information transfer across neural networks in the brain of individuals with ASD. Although most studies revealed underconnectivity in individuals with ASD, Kikuchi et al., (2013) observed increased functional connectivity in the bilateral anterior PFC in children with ASD. Notably, this finding was based on relatively high-frequency spontaneous fluctuation at $0.02 \mathrm{~Hz}$, rather than 0.01-0.1 $\mathrm{Hz}$ that has predominantly been used for functional connectivity research. More research on this issue is needed to help us better understand the changes in functional connectivity in individuals with ASD.

Studies have shown that functional network efficiency, as measured by fNIRS, can be applied as a neural biomarker to discriminate ASD from TDC ( $\mathrm{Li}$ et al., 2016; $\mathrm{Li}$ and $\mathrm{Yu}, 2016$ ). For instance, $\mathrm{Li}$ and $\mathrm{Yu}$ (2016) used the K-means method and J.Li and colleagues (2016) used a support vector machine to distinguish children with ASD from the TDC. These studies suggest that fNIRS has the potential to become an auxiliary tool when screening individuals for ASD using the obtained hemodynamic data.

\subsection{Future directions}

\subsubsection{Infants and longitudinal research}

There is an ongoing debate over the origins and development of ASD. Previous ASD research has raised several important questions, like (1) how does the immature brain functionally represent external input from birth? and (2) to what extent do social experience and environment facilitate the development of children with ASD as they grow up? To solve 
these issues, further exploration of the early brain development in ASD is needed. To date, however, not enough effort has been put in the examination of developmental characteristics of the ASD brain from an early stage. Although recent research has made contributions to our knowledge of alterations of brain functions in adults with ASD (Kleinhans et al., 2016; Murphy et al., 2014), only a limited number of studies have investigated the neural mechanisms in babies or young children. Two possible explanations for the lack of these studies are the limitations of neuroimaging techniques when it comes to infant's studies and the difficulties of detecting early autism. All these factors point to the importance of neuroimaging studies, among which fNIRS and EEG are more recommended, in infants at risk of ASD during prospective follow-up studies.

With the benefits of fNIRS in early investigations and longitudinal studies, future work focusing on the early characterization and its changes in ASD is likely to be vital for elucidating the etiology of ASD. As mentioned earlier, the characteristics of HR infants can help us to have an initial understanding of early features of ASD. Some studies (Keehn et al., 2013; Redcay and Courchesne, 2005) indicate that abnormalities in early brain function may have existed in the first year of ASD, which facilitates researchers to focus on a younger age group when examining ASD. Meanwhile, converging evidence strongly suggests the critical role of age in the ongoing behavioural symptoms (Wallace et al., 2017) and brain growth (Courchesne et al., 2011) of individuals with ASD. Longitudinal studies of HR infants help us explore the age-related growth trajectory and the 'endophenotypes' (Gottesman and Gould, 2003) that often involve neurophysiology and neuroanatomy. The follow-up study by Lloyd-Fox and colleagues (2017) indicated a potential correlation between early atypical processing at the age of 4 to 6 months old and later social behaviour at 3 years of age.

\subsubsection{Clinical application}

One important objective of ASD research is to apply our understanding of the disorder to improve early detection and intervention. In this respect, attention has recently shifted to the discovery of biomarkers and possibilities of using fNIRS for interventions. Since early clinical diagnosis of ASD (e.g., in 18-months-olds or 24-months-olds) based on observable atypical behaviour may often not be as stable as at three years of age (Zwaigenbaum et al., 2016), physiological biomarkers at a young age is of great value for the diagnosis of ASD at a young age. The valid spatial-temporal resolution and applicability for studying developmental disorders make fNIRS a promising imaging method to discover biomarkers that can distinguish young children with ASD from a TDC population. Although we are currently unable to employ fNIRS to diagnose ASD in infants, the growing body of evidence supports the potential clinical usage of this instrument. The studies mentioned earlier suggest several promising biomarkers from fNIRS for ASD detection, such as the network efficiency in the PFC ( $\mathrm{Li}$ and $\mathrm{Yu}$, 2016) and hemodynamic changes in the temporal cortex (Ichikawa et al., 2014).

Neurofeedback training, which enables participants to regulate their brain function and improve behavioural performance through the real-time feedback of neural signals, has been extended to fNIRS studies (Liu et al., 2017; Narita, 2015). Based on the neurofeedback approach and potential biomarkers obtained from fNIRS, the fNIRS-based neurofeedback has been considered as a relatively new and flourishing technique for therapeutic intervention. For instance, a training method has been proposed based on self-regulation of oxy-hemoglobin during facial recognition, by which the participant with ASD who received real-feedback showed more behavioural improvement during facial recognition compared to another participant with ASD who received sham-feedback (Liu et al., 2017). However, the pragmatic application of fNIRS still has problems, such as the technical immaturity of fNIRS-based neurofeedback, the lack of standardized analysis for hemodynamic data, and the shortage of biomarkers obtained from HR infants. Effort is therefore required to first discover suitable physiological 
biomarkers with acceptable accuracy for the diagnosis and treatment of ASD, and to improve their reliability in the clinical environment. All of these efforts will support the development of a neurofeedback technique based on fNIRS to play a part in the future therapeutic interventions of ASD.

\subsubsection{Multimodality integration of techniques}

Integration of different technologies allows us to look at the same issue from multiple perspectives. The combination of the fNIRS with other neural or behavioural techniques should be encouraged, as it will allow us to obtain more information from the same participant under a certain task setting. The limited spatial resolution of fNIRS, as mentioned earlier, makes it difficult to localize the spatial origins of hemodynamic response, which may be addressed by an anatomicalfunctional co-registration with magnetic resonance imaging (MRI) (Lloyd-Fox et al., 2014; Tsuzuki and Dan, 2014; Wijeakumar et al., 2015) or diffuse optical tomography (DOT) (Chalia et al., 2016; Chitnis et al., 2016; Eggebrecht et al., 2014; Ferradal et al., 2016). Compared with fNIRS, structural MRI provides excellent anatomical detail, which makes it valuable to combine these two modalities. In the study of Lloyd-Fox and colleagues (2014), the hemodynamic response in several social brain regions, including IFG, MTG-STG, pSTS-TPJ, were neuroanatomically localized based on the fNIRSMRI co-registration scalp map for 4-7 months old infants. DOT, as an extension of fNIRS that reconstructs three-dimensional maps of changes in the hemodynamic concentration, is an effective technology for mapping the human brain with great spatial resolution (Chitnis et al., 2016; Eggebrecht et al., 2014). Combing this spatial advantage of DOT with fNIRS, it could provide a more reliable result when examining the brain functions of ASD using NIR light. Further studies of fNIRS that register to a valid anatomical template, rather than being limited to 10-20 coordinates, may improve our understanding of the neurological manifestations in ASD.

Apart from the co-registration approach to improve the spatial localization of fNIRS, a bimodal EEG/MEG measurement may also turn out to be valuable for the study of ASD. The combination of these techniques allows us to simultaneously measure neuronal activity and cortical hemodynamics (Seki et al., 2018) in individuals with ASD. Although the spatial resolution is inferior to fMRI, fNIRS has acceptable spatial positioning by measuring the changes of local cerebral blood oxygen between each pair of optodes, as well as good tolerance for head motion (Tsuzuki and Dan, 2014). In contrast, both EEG and MEG have relative high temporal resolution but measure whole-head electrical signals. These factors make it interesting to investigate the temporal-spatial features of brain processing based on the synchronous measurement of fNIRS and EEG/MEG (Ge et al., 2017; Telkemeyer et al., 2011). Certainly, fNIRS coupled with behavioural examination, such as the Eye-tracking to measure eye-movement trajectory (Kita et al., 2011) or the ADOS to estimate the severity of symptoms (Kikuchi et al., 2013), is undisputedly important to address the relationship between the physiological substrates and symptom manifestation in this disorder.

\subsection{Challenges}

Although effort has been made to use fNIRS for ASD studies, there are still several potential challenges worth of noticing. In addition to the issues mentioned above, regarding the small number of participants and the inconsistencies in instrument parameters (see 4.1 for details), we also list the following important challenges when employing fNIRS in ASD studies.

\subsubsection{Motion artifacts}


One of the crucial issues concerns the susceptibility of fNIRS to motion-induced artifacts, a significant source of noise in the signal. This challenge exists in most fNIRS studies but is of importance when examining children with ASD who are often more hypersensitive or overreactive than a typically developing population and difficult to keep still. Also, the lack of well-established analysis methods for reducing motion artifacts deteriorates this problem. At the present time, removing motion artefacts relies mainly on discarding trials or using correction techniques, which varies greatly across laboratories. Although there is scientific interest in this matter, e.g. in studies comparing the performance of different motion artifact correction techniques (Brigadoi et al., 2014; Cooper et al., 2012), further work is still required to develop a standardized preprocessing pipeline to lessen the impact of motion-artifacts.

\subsubsection{Localization and interpretation}

Another unanswered question refers to the origin of neural activation as measured by fNIRS. Since fNIRS measures hemodynamic response from the surface cortical areas, the information from the subcortical areas (e.g., deeper than $3 \mathrm{~cm}$ below the scalp surface) might be neglected. At the same time, the spatial resolution of fNIRS is not as accurate as that of fMRI, and it is difficult to distinguish exactly which brain area contributes to the signals captured by the instrument. In spite of several more precise ways to resolve this problem, such as anatomical-functional co-registration, the most common solution in current fNIRS research is to use the international 10-20 system to localize the probe position (Wilcox and Biondi, 2015). This can easily cause inaccurate positioning and interpretation of the results because of the unknown relationship between external probe placements and internal structures of the ASD brain.

In addition to these methodological challenges, it is desirable to be cautious when interpreting fNIRS results based on hemodynamic response in ASD, especially with infants and children. The hemodynamic response is possibly modulated by several factors such as experimental design, age of participants, or the involved cortical regions (Issard and Gervain, 2018). Future fNIRS studies should take these factors into account when designing experiments and discussing findings.

$5 \quad$ Limitations of the current review

In this review, we have systematically searched relevant articles concerning brain functions in individuals with ASD using fNIRS and have described their contribution to ASD research. It is not possible, however, to combine data taken from various studies with statistical approaches (e.g., meta-analysis), since only a small amount of studies uses similar tasks to study the same brain function. The discrepancies in optodes placement (e.g., source-detector distance and amount) across laboratories may lead to different localizations of brain regions measured throughout studies. This fact also makes it more difficult to compare studies. In this review, studies have been allocated to specific domains (e.g., social, language, working memory, and inhibition) according to the experimental tasks. We have striven to classify them accurately yet acknowledge that there is some overlap. For example, as we mentioned earlier, the study by Gallagher et al. (2007) was assigned to the category of language rather than executive functions. Finally, there seems to be some participants overlap between studies published by researchers from the same laboratory, which may affect our estimates of the ASD population taking part in fNIRS research.

\section{Conclusion}

By examining the hemodynamic response in individuals with ASD and HR infants, fNIRS has been used to explore both task-triggered activation and intrinsic functional connectivity in the ASD population. Findings of fNIRS studies in ASD provide further evidence for brain dysfunction in ASD, extending to a variety of aspects including social, communicative and 
executive functions. Deficiencies in cortical activation and functional connectivity in individuals with ASD have been observed in a wide range of brain regions, such as the prefrontal cortex, the inferior frontal gyrus, the middle and superior temporal gyrus. Moreover, research of the fNIRS studies in ASD suggests that trajectory variations in the brain of people with ASD may differ from those in TDC, and these variations may emerge from an early age on. The technical advantages of fNIRS make it more conducive in the measurement of early brain functions and their developmental path in infants at risk of ASD and children diagnosed with ASD, which can be deemed as the most promising field for fNIRS in ASD research. In addition, in our opinion, fNIRS is to be encouraged for clinical applications in ASD, and researchers should be stimulated to use fNIRS together with other techniques so as to enable a better interpretation of observations. Finally, it needs to be acknowledged that this research area is still at an early stage and there are several challenges in the current research that need to be resolved in the future.

\section{Conflict of interest}

The authors declare that they have no conflict of interest.

\section{Funding}

This research was supported by a grant from the project of State Scholarship Fund organized by China Scholarship Council (No.201606750005).

\section{References}

Abrams, D.A., Lynch, C.J., Cheng, K.M., Phillips, J., Supekar, K., Ryali, S., Uddin, L.Q., Menon, V., 2013. Underconnectivity between voice-selective cortex and reward circuitry in children with autism. Proc. Natl. Acad. Sci. 110, 12060-12065. https://doi.org/10.1073/pnas.1302982110

American Psychiatric Association, 2013. Diagnostic and statistical manual of mental disorders (DSM-5®). Am. Psychiatr. Pub.

Baker, W.B., Parthasarathy, A.B., Busch, D.R., Mesquita, R.C., Greenberg, J.H., Yodh, A.G., 2014. Modified Beer-Lambert law for blood flow. Biomed. Opt. Express 5, 4053. https://doi.org/10.1364/BOE.5.004053

Baron-Cohen, S., 2001. Theory of mind and autism: A review. Spec. Issues Int. Rev. Res. Ment. Retard. 23, $169-184$. https://doi.org/http://dx.doi.org/10.1016/S0074-7750(00)80010-5

Bölte, S., Marschik, P.B., Falck-Ytter, T., Charman, T., Roeyers, H., Elsabbagh, M., 2013. Infants at risk for autism: a European perspective on current status, challenges and opportunities. Eur. Child Adolesc. Psychiatry 22, 341-8. https://doi.org/10.1007/s00787-012-0368-4

Braukmann, R., Lloyd-Fox, S., Blasi, A., Johnson, M.H., Bekkering, H., Buitelaar, J.K., Hunnius, S., 2017. Diminished socially selective neural processing in 5-month-old infants at high familial risk of autism. Eur. J. Neurosci. 1-9. https://doi.org/10.1111/ejn.13751

Brigadoi, S., Ceccherini, L., Cutini, S., Scarpa, F., Scatturin, P., Selb, J., Gagnon, L., Boas, D.A., Cooper, R.J., 2014. Motion artifacts in functional near-infrared spectroscopy: A comparison of motion correction techniques applied to real cognitive data. Neuroimage 85, 181-191. https://doi.org/10.1016/j.neuroimage.2013.04.082

Chalia, M., Lee, C.W., Dempsey, L.A., Edwards, A.D., Singh, H., Michell, A.W., Everdell, N.L., Hill, R.W., Hebden, J.C., Austin, T., Cooper, R.J., 2016. Hemodynamic response to burst-suppressed and discontinuous electroencephalography activity in infants with hypoxic ischemic encephalopathy. Neurophotonics 3, 31408 .

https://doi.org/10.1117/1.NPh.3.3.031408

Chaudhary, U., Hall, M., Gutierrez, A., Messinger, D., Rey, G., Godavarty, A., 2011. Joint attention studies in normal and 
autistic children using NIRS, in: SPIE BiOS. p. 788348. https://doi.org/10.1117/12.874360

Centers for Disease Control and Prevention., 2014. Prevalence of Autism Spectrum Disorder Among Children Aged 8 Years - Autism and Developmental Disabilities Monitoring Network, 11 Sites , United States, 2014

Chitnis, D., Cooper, R.J., Dempsey, L., Powell, S., Quaggia, S., Highton, D., Elwell, C., Hebden, J.C., Everdell, N.L., 2016. Functional imaging of the human brain using a modular, fibre-less, high-density diffuse optical tomography system. Biomed. Opt. Express 7, 4275. https://doi.org/10.1364/BOE.7.004275

Christensen, D.L., Baio, J., Braun, K.V.N., Bilder, D., Charles, J., Constantino, J.N., Daniels, J., Durkin, M.S., Fitzgerald, R.T., Kurzius-Spencer, M., Lee, L.-C., Pettygrove, S., Robinson, C., Schulz, E., Wells, C., Wingate, M.S., Zahorodny, W., Yeargin-Allsopp, M., 2016. Prevalence and Characteristics of Autism Spectrum Disorder Among Children Aged 8 Years - Autism and Developmental Disabilities Monitoring Network, 11 Sites, United States, 2012. MMWR. Surveill. Summ. 65, 1-23. https://doi.org/10.15585/mmwr.ss6503a1

Cooper, R.J., Selb, J., Gagnon, L., Phillip, D., Schytz, H.W., Iversen, H.K., Ashina, M., Boas, D.A., 2012. A systematic comparison of motion artifact correction techniques for functional near-infrared spectroscopy. Front. Neurosci. https://doi.org/10.3389/fnins.2012.00147

Corbett, B. a., Constantine, L.J., Hendren, R., Rocke, D., Ozonoff, S., 2010. Examining executive functioning in children with autism spectrum disorder, attention deficit hyperactivity disorder and typical development. Psychiatry Res. 166, 210-222. https://doi.org/10.1016/j.psychres.2008.02.005

Courchesne, E., Campbell, K., Solso, S., 2011. Brain growth across the life span in autism: Age-specific changes in anatomical pathology. Brain Res. 1380, 138-145. https://doi.org/10.1016/j.brainres.2010.09.101

Ebisch, S.J.H., Gallese, V., Willems, R.M., Mantini, D., Groen, W.B., Romani, G.L., Buitelaar, J.K., Bekkering, H., 2011. Altered intrinsic functional connectivity of anterior and posterior insula regions in high-functioning participants with autism spectrum disorder. Hum. Brain Mapp. 32, 1013-1028. https://doi.org/10.1002/hbm.21085

Edwards, L.A., Wagner, J.B., Tager-Flusberg, H., Nelson, C.A., 2017. Differences in Neural Correlates of Speech Perception in 3 Month Olds at High and Low Risk for Autism Spectrum Disorder. J. Autism Dev. Disord. 47, 3125-3138. https://doi.org/10.1007/s10803-017-3222-1

Eggebrecht, A.T., Ferradal, S.L., Robichaux-Viehoever, A., Hassanpour, M.S., Dehghani, H., Snyder, A.Z., Hershey, T., Culver, J.P., 2014. Mapping distributed brain function and networks with diffuse optical tomography. Nat. Photonics 8 , 448-454. https://doi.org/10.1038/nphoton.2014.107

Elsabbagh, M., Divan, G., Koh, Y.J., Kim, Y.S., Kauchali, S., Marcín, C., Montiel-Nava, C., Patel, V., Paula, C.S., Wang, C., Yasamy, M.T., Fombonne, E., 2012. Global Prevalence of Autism and Other Pervasive Developmental Disorders. Autism Res. 5, 160-179. https://doi.org/10.1002/aur.239

Elsabbagh, M., Johnson, M.H., 2016. Autism and the Social Brain: The First-Year Puzzle. Biol. Psychiatry. https://doi.org/10.1016/j.biopsych.2016.02.019

Ernst, L.H., Schneider, S., Ehlis, A.C., Fallgatter, A.J., 2012. Review: Functional near infrared spectroscopy in psychiatry: A critical revie. J. Near Infrared Spectrosc. 20, 93-105. https://doi.org/10.1255/jnirs.970

Ferradal, S.L., Liao, S.M., Eggebrecht, A.T., Shimony, J.S., Inder, T.E., Culver, J.P., Smyser, C.D., 2016. Functional Imaging of the Developing Brain at the Bedside Using Diffuse Optical Tomography. Cereb. Cortex 26, 1558-1568. https://doi.org/10.1093/cercor/bhu320

Ferrari, M., Quaresima, V., 2012. A brief review on the history of human functional near-infrared spectroscopy (fNIRS) development and fields of application. Neuroimage 63, 921-935. https://doi.org/10.1016/j.neuroimage.2012.03.049

Fox, S.E., Wagner, J.B., Shrock, C.L., Tager-Flusberg, H., Nelson, C.A., 2013. Neural Processing of Facial Identity and Emotion in Infants at High-Risk for Autism Spectrum Disorders. Front. Hum. Neurosci. 7, 1-18. https://doi.org/10.3389/fnhum.2013.00089

Friston, K.J., 2011. Functional and Effective Connectivity: A Review. Brain Connect. 1, 13-36. https://doi.org/10.1089/brain.2011.0008

Funabiki, Y., Murai, T., Toichi, M., 2012a. Cortical activation during attention to sound in autism spectrum disorders. Res. Dev. Disabil. 33, 518-524. https://doi.org/10.1016/j.ridd.2011.10.016

Funabiki, Y., Murai, T., Toichi, M., 2012b. Research in Developmental Disabilities Cortical activation during attention to sound in autism spectrum disorders. Res. Dev. Disabil. 33, 518-524. https://doi.org/10.1016/j.ridd.2011.10.016 
Gallagher, A., Thériault, M., Maclin, E., Low, K., Gratton, G., Fabiani, M., Gagnon, L., Valois, K., Rouleau, I., Sauerwein, H.C., Carmant, L., Nguyen, D.K., Lortie, A., Lepore, F., Béland, R., Lassonde, M., 2007. Near-infrared spectroscopy as an alternative to the Wada test for language mapping in children, adults and special populations. Epileptic Disord. 9, 241-255. https://doi.org/10.1684/epd.2007.0118

Ge, S., Ding, M.Y., Zhang, Z., Lin, P., Gao, J.F., Wang, R.M., Sun, G.P., Iramina, K., Deng, H.H., Yang, Y.K., Leng, Y., 2017. Temporal-Spatial Features of Intention Understanding Based on EEG-fNIRS Bimodal Measurement. IEEE Access 5, 14245-14258. https://doi.org/10.1109/ACCESS.2017.2723428

Gervain, J., 2014. Near-infrared spectroscopy: recent advances in infant speech perception and language acquisition research. Front. Psychol. 5, 1-2. https://doi.org/10.3389/fpsyg.2014.00916

Gervain, J., Mehler, J., Werker, J.F., Nelson, C.A., Csibra, G., Lloyd-Fox, S., Shukla, M., Aslin, R.N., 2011. Near-infrared spectroscopy: A report from the McDonnell infant methodology consortium. Dev. Cogn. Neurosci. https://doi.org/10.1016/j.den.2010.07.004

Gottesman, I.I., Gould, T.D., 2003. The Endophenotype Concept in Psychiatry: Etymology and Strategic Intentions. Am. J. Psychiatry 160, 636-645. https://doi.org/10.1176/appi.ajp.160.4.636

Harms, M.B., Martin, A., Wallace, G.L., 2010. Facial emotion recognition in autism spectrum disorders: A review of behavioral and neuroimaging studies. Neuropsychol. Rev. 20, 290-322. https://doi.org/10.1007/s11065-010-9138-6

Higgins, JPT., Green S., 2011. Cochrane Handbook for Systematic Reviews of Interventions Version 5.1.0. The Cochrane Collaboration. http://handbook.cochrane.org.

Ichikawa, H., Kitazono, J., Nagata, K., Manda, A., Shimamura, K., Sakuta, R., Okada, M., Yamaguchi, M.K., Kanazawa, S., Kakigi, R., 2014. Novel method to classify hemodynamic response obtained using multi-channel fNIRS measurements into two groups: exploring the combinations of channels. Front. Hum. Neurosci. 8, 1-10. https://doi.org/10.3389/fnhum.2014.00480

Ishii-Takahashi, A., Takizawa, R., Nishimura, Y., Kawakubo, Y., Kuwabara, H., Matsubayashi, J., Hamada, K., Okuhata, S., Yahata, N., Igarashi, T., Kawasaki, S., Yamasue, H., Kato, N., Kasai, K., Kano, Y., 2014. Prefrontal activation during inhibitory control measured by near-infrared spectroscopy for differentiating between autism spectrum disorders and attention deficit hyperactivity disorder in adults. NeuroImage Clin. 4, 53-63. https://doi.org/10.1016/j.nicl.2013.10.002

Issard, C., Gervain, J., 2018. Variability of the hemodynamic response in infants: Influence of experimental design and stimulus complexity. Dev. Cogn. Neurosci. https://doi.org/10.1016/j.den.2018.01.009

Itahashi, T., Yamada, T., Watanabe, H., Nakamura, M., Ohta, H., Kanai, C., Iwanami, A., Kato, N., Hashimoto, R., 2015. Alterations of local spontaneous brain activity and connectivity in adults with high-functioning autism spectrum disorder. Mol. Autism 6, 30. https://doi.org/10.1186/s13229-015-0026-z

Iwanaga, R., Tanaka, G., Nakane, H., Honda, S., Imamura, A., Ozawa, H., 2013. Usefulness of near-infrared spectroscopy to detect brain dysfunction in children with autism spectrum disorder when inferring the mental state of others. Psychiatry Clin. Neurosci. 67, 203-209. https://doi.org/10.1111/pcn.12052

Iwanami, A., Okajima, Y., Ota, H., Tani, M., Yamada, T., Hashimoro, R., Kanai, C., Watanabe, H., Yamasue, H., Kawakubo, Y., Kato, N., 2011. Task dependent prefrontal dysfunction in persons with Asperger's disorder investigated with multichannel near-infrared spectroscopy. Res. Autism Spectr. Disord. 5, 1187-1193. https://doi.org/10.1016/j.rasd.2011.01.005

Iwanami, A., Okajima, Y., Ota, H., Tani, M., Yukawa, Y., Kanai, C., Yamada, T., Kawakubo, Y., Yamasue, H., Kato, N., 2010. Frontal dysfunction during a cognitive task in persons with Asperger disorder investigated with multi-channel near-infrared spectroscopy. Int. J. Psychophysiol. 77, 255-255. https://doi.org/10.1016/j.ijpsycho.2010.06.073

Jung, C.E., Strother, L., Feil-Seifer, D.J., Hutsler, J.J., 2016. Atypical asymmetry for processing human and robot faces in autism revealed by fNIRS. PLoS One 11, 1-13. https://doi.org/10.1371/journal.pone.0158804

Just, M.A., Keller, T.A., Malave, V.L., Kana, R.K., Varma, S., 2012. Autism as a neural systems disorder: A theory of frontal-posterior underconnectivity. Neurosci. Biobehav. Rev. 36, 1292-1313. https://doi.org/10.1016/j.neubiorev.2012.02.007

Kajiume, A., Aoyama-Setoyama, S., Saito-Hori, Y., Ishikawa, N., Kobayashi, M., 2013. Reduced brain activation during imitation and observation of others in children with pervasive developmental disorder: a pilot study. Behav. Brain Funct. 9, 21. https://doi.org/10.1186/1744-9081-9-21 
Kana, R.K., Keller, T.A., Cherkassky, V.L., Minshew, N.J., Just, M.A., 2009. Atypical frontal-posterior synchronization of Theory of Mind regions in autism during mental state attribution. Soc. Neurosci. 4, 135-152. https://doi.org/10.1080/17470910802198510

Kana, R.K., Uddin, L.Q., Kenet, T., Chugani, D., MÃ¹/4ler, R.-A., 2014. Brain connectivity in autism. Front. Hum. Neurosci. 8, 8-11. https://doi.org/10.3389/fnhum.2014.00349

Kawakubo, Y., Kuwabara, H., Watanabe, K.I., Minowa, M., Someya, T., Minowa, I., Kono, T., Nishida, H., Sugiyama, T., Kato, N., Kasai, K., 2009. Impaired prefrontal hemodynamic maturationin autism and unaffected siblings. PLoS One 4, 6-13. https://doi.org/10.1371/journal.pone.0006881

Keehn, B., Wagner, J.B., Tager-Flusberg, H., Nelson, C.A., 2013. Functional connectivity in the first year of life in infants atrisk for autism: a preliminary near-infrared spectroscopy study. Front. Hum. Neurosci. 7, 1-10. https://doi.org/10.3389/fnhum.2013.00444

Keown, C., Shih, P., Nair, A., Peterson, N., Mulvey, M., Müller, R.A., 2013. Local functional overconnectivity in posterior brain regions is associated with symptom severity in autism spectrum disorders. Cell Rep. 5, 567-572. https://doi.org/10.1016/j.celrep.2013.10.003

Kikuchi, M., Yoshimura, Y., Shitamichi, K., Ueno, S., Hiraishi, H., Munesue, T., Hirosawa, T., Ono, Y., Tsubokawa, T., Inoue, Y., Oi, M., Niida, Y., Remijn, G.B., Takahashi, T., Suzuki, M., Higashida, H., Minabe, Y., 2013. Anterior Prefrontal Hemodynamic Connectivity in Conscious 3- to 7-Year-Old Children with Typical Development and Autism Spectrum Disorder. PLoS One 8. https://doi.org/10.1371/journal.pone.0056087

Kita, Y., Gunji, A., Inoue, Y., Goto, T., Sakihara, K., Kaga, M., Inagaki, M., Hosokawa, T., 2011. Self-face recognition in children with autism spectrum disorders: A near-infrared spectroscopy study. Brain Dev. 33, 494-503. https://doi.org/10.1016/j.braindev.2010.11.007

Kleinhans, N.M., Richards, T., Greenson, J., Dawson, G., Aylward, E., 2016. Altered Dynamics of the fMRI Response to Faces in Individuals with Autism. J. Autism Dev. Disord. 46, 232-241. https://doi.org/10.1007/s10803-015-2565-8

Knaus, T.A., Silver, A.M., Kennedy, M., Lindgren, K.A., Dominick, K.C., Siegel, J., Tager-Flusberg, H., 2010. Language laterality in autism spectrum disorder and typical controls: A functional, volumetric, and diffusion tensor MRI study. Brain Lang. 112, 113-120. https://doi.org/10.1016/j.bandl.2009.11.005

KNAUS, T.A., SILVER, A.M., LINDGREN, K.A., HADJIKHANI, N., TAGER-FLUSBERG, H., 2008. fMRI activation during a language task in adolescents with ASD. J. Int. Neuropsychol. Soc. 14, 967. https://doi.org/10.1017/S1355617708081216

Kuwabara, H., Kasai, K., Takizawa, R., Kawakubo, Y., Yamasue, H., Rogers, M.A., Ishijima, M., Watanabe, K., Kato, N., 2006. Decreased prefrontal activation during letter fluency task in adults with pervasive developmental disorders: A near-infrared spectroscopy study. Behav. Brain Res. 172, 272-277. https://doi.org/10.1016/j.bbr.2006.05.020

Kwakye, L.D., Foss-Feig, J.H., Cascio, C.J., Stone, W.L., Wallace, M.T., 2011. Altered Auditory and Multisensory Temporal Processing in Autism Spectrum Disorders. Front. Integr. Neurosci. 4, 1-11. https://doi.org/10.3389/fnint.2010.00129

Lee, M.H., Smyser, C.D., Shimony, J.S., 2013. Resting-state fMRI: A review of methods and clinical applications. Am. J. Neuroradiol. 34, 1866-1872. https://doi.org/10.3174/ajnr.A3263

Li, J., Qiu, L., Xu, L., Pedapati, E. V., Erickson, C.A., Sunar, U., 2016. Characterization of autism spectrum disorder with spontaneous hemodynamic activity. Biomed. Opt. Express 7, 3871-3781. https://doi.org/10.1364/BOE.7.003871

Li, Y., Yu, D., 2016. Weak network efficiency in young children with Autism Spectrum Disorder: Evidence from a functional near-infrared spectroscopy study. Brain Cogn. 108, 47-55. https://doi.org/10.1016/j.bandc.2016.07.006

Liu, N., Cliffer, S., Pradhan, A.H., Lightbody, A., Hall, S.S., Reiss, A.L., 2017. Optical-imaging-based neurofeedback to enhance therapeutic intervention in adolescents with autism: methodology and initial data. Neurophotonics 4, $011003-$ 011003. https://doi.org/10.1117/1.NPh.4.1.011003

Liu, T., Liu, X., Yi, L., Zhu, C., Markey, P.S., Pelowski, M., 2017. Assessing autism at its social and developmental roots: A review of Autism Spectrum Disorder studies using functional near-infrared spectroscopy. Neuroimage 1-13. https://doi.org/10.1016/j.neuroimage.2017.09.044

Lloyd-Fox, S., Blasi, A., Elwell, C.E., 2010. Illuminating the developing brain: The past, present and future of functional near infrared spectroscopy. Neurosci. Biobehav. Rev. 34, 269-284. https://doi.org/10.1016/j.neubiorev.2009.07.008

Lloyd-Fox, S., Blasi, A., Elwell, C.E., Charman, T., Murphy, D., Johnson, M.H., 2013. Reduced neural sensitivity to social 
stimuli in infants at risk for autism. Proc. R. Soc. B Biol. Sci. 280, 20123026-20123026.

https://doi.org/10.1098/rspb.2012.3026

Lloyd-Fox, S., Blasi, A., Pasco, G., Gliga, T., Jones, E.J.H., Murphy, D.G.M., Elwell, C.E., Charman, T., Johnson, M.H., 2017. Cortical responses before 6 months of life associate with later autism. Eur. J. Neurosci. 1-14. https://doi.org/10.1111/ejn.13757

Lloyd-Fox, S., Richards, J.E., Blasi, A., Murphy, D.G.M., Elwell, C.E., Johnson, M.H., 2014. Coregistering functional nearinfrared spectroscopy with underlying cortical areas in infants. Neurophotonics 1, 25006. https://doi.org/10.1117/1.NPh.1.2.025006

Loomes, R., Hull, L., Polmear, W., Mandy, L., 2017. What Is the Male-to-Female Ratio in Autism? A Systematic Review and Meta-Analysis. J. Am. Acad. Child Adolesc. Psychiatry 56, 466-474. https://doi.org/10.1016/j.jaac.2017.03.013

Maenner, M.J., Rice, C.E., Arneson, C.L., Cunniff, C., Schieve, L.A., Carpenter, L.A., Van Naarden Braun, K., Kirby, R.S., Bakian, A. V, Durkin, M.S., 2014. Potential impact of DSM-5 criteria on autism spectrum disorder prevalence estimates. JAMA psychiatry 71, 292-300. https://doi.org/10.1001/jamapsychiatry.2013.3893

Maximo, J.O., Cadena, E.J., Kana, R.K., 2014. The implications of brain connectivity in the neuropsychology of autism. Neuropsychol. Rev. 24, 16-31. https://doi.org/10.1007/s11065-014-9250-0

Minagawa-Kawai, Y., Naoi, N., Kikuchi, N., Yamamoto, J., Nakamura, K., Kojima, S., 2009. Cerebral laterality for phonemic and prosodic cue decoding in children with autism. Neuroreport 20, 1219-1224. https://doi.org/10.1097/WNR.0b013e32832fa65f

Monk, C., 2010. Neural circuitry of emotional face processing in autism spectrum disorders. J. Psychiatry Neurosci. 35, 105114. https://doi.org/10.1503/jpn.090085

Mori, K.K., Toda, Y., Ito, H., Mori, T., Mori, K.K., Goji, A., Hashimoto, H., Tani, H., Miyazaki, M., Harada, M., Kagami, S., 2015. Neuroimaging in autism spectrum disorders: 1H-MRS and NIRS study. J. Med. Invest. 62, 29-36. https://doi.org/10.2152/jmi.62.29

Murphy, C.M., Christakou Ph.D, A., Daly, E.M., Ecker, C., Giampietro, V., Brammer, M., Smith, A.B., Johnston, P., Robertson, D.M., Murphy, D.G., Rubia, K., Bailey, A.J., Baron-Cohen, S., Bolton, P.F., Bullmore, E.T., Carrington, S., Chakrabarti, B., Daly, E.M., Deoni, S.C., Ecker, C., Happe, F., Henty, J., Jezzard, P., Johnston, P., Jones, D.K., Lombardo, M., Madden, A., Mullins, D., Murphy, C.M., Murphy, D.G., Pasco, G., Sadek, S., Spain, D., Steward, R., Suckling, J., Wheelwright, S., Williams, S.C., 2014. Abnormal functional activation and maturation of fronto-striatotemporal and cerebellar regions during sustained attention in autism spectrum disorder. Am. J. Psychiatry 171, 11071116. https://doi.org/10.1176/appi.ajp.2014.12030352

Nakadoi, Y., Sumitani, S., Watanabe, Y., Akiyama, M., Yamashita, N., Ohmori, T., 2012. Multi-channel near-infrared spectroscopy shows reduced activation in the prefrontal cortex during facial expression processing in pervasive developmental disorder. Psychiatry Clin. Neurosci. 66, 26-33. https://doi.org/10.1111/j.1440-1819.2011.02290.x

Narita, N., 2015. Application of NIRS as a non-invasive and supportive tool for Autism spectrum disorders. 生体医工学 53(Supplem, 366-368.

Narita, N., Saotome, A., Higuchi, H., Narita, M., Tazoe, M., Sakatani, K., 2012. Impaired prefrontal cortical response by switching stimuli in autism spectrum disorders. J. Pediatr. Neurol. 10, 87-94. https://doi.org/10.3233/JPN-2012-0541

Paynter, J.M., Keen, D., Rose, V.J., 2016. Systematic review documents limited empirical support for the practical application of the Theory of Mind model of ASD. Evid. Based. Commun. Assess. Interv. 9539, 1-9. https://doi.org/10.1080/17489539.2016.1265698

Pelphrey, K.A., Shultz, S., M.Hudac, C., Wyk, B.C. Vander, 2012. Constrainning Heterogeneity: The Social Brain and its Development in Autism Spectrum Disorder. J. psychiatry Neurosci. 52, 631-644. https://doi.org/10.1111/j.14697610.2010.02349.x

Philip, R.C.M., Dauvermann, M.R., Whalley, H.C., Baynham, K., Lawrie, S.M., Stanfield, A.C., 2012. A systematic review and meta-analysis of the fMRI investigation of autism spectrum disorders. Neurosci. Biobehav. Rev. 36, 901-942. https://doi.org/10.1016/j.neubiorev.2011.10.008

Raichle, M.E., Mintun, M.A., 2006. Brain Work and Brain Imaging. Annu. Rev. Neurosci. 29, 449-476. https://doi.org/10.1146/annurev.neuro.29.051605.112819 
Redcay, E., 2008. The superior temporal sulcus performs a common function for social and speech perception: Implications for the emergence of autism. Neurosci. Biobehav. Rev. 32, 123-142. https://doi.org/10.1016/j.neubiorev.2007.06.004

Redcay, E., Courchesne, E., 2005. When is the brain enlarged in autism? A meta-analysis of all brain size reports. Biol. Psychiatry 58, 1-9. https://doi.org/10.1016/j.biopsych.2005.03.026

Sandin, S., Lichtenstein, P., Kuja-Halkola, R., Larsson, H., Hultman, C.M., Reichenberg, A., 2014. The Familial Risk of Autism. JAMA 311, 1770-1777. https://doi.org/10.1001/jama.2014.4144

Seki, Y., Miyashita, T.; Kandori, A., Maki, A.;, Koizumi, H., 2018. Simultaneous measurement of neuronal activity and cortical hemodynamics by unshielded magnetoencephalography and near-infrared spectroscopy. J. Biomed. Opt. 17, 107001. https://doi.org/10.1117/1.JBO.17.10.107001

Siddiqui, M.F., Lloyd-Fox, S., Kaynezhad, P., Tachtsidis, I., Johnson, M.H., Elwell, C.E., 2017. Non-invasive measurement of a metabolic marker of infant brain function. Sci. Rep. 7, 1330. https://doi.org/10.1038/s41598-017-01394-z

Sporns, O., 2013. Network attributes for segregation and integration in the human brain. Curr. Opin. Neurobiol. 23, $162-171$. https://doi.org/10.1016/j.conb.2012.11.015

Sporns, O., 2003. Network Analysis, Complexity, and Brain Function 8, 56-60.

Tamura, R., Kitamura, H., Endo, T., Abe, R., Someya, T., 2012. Decreased leftward bias of prefrontal activity in autism spectrum disorder revealed by functional near-infrared spectroscopy. Psychiatry Res. - Neuroimaging 203, 237-240. https://doi.org/10.1016/j.pscychresns.2011.12.008

Telkemeyer, S., Rossi, S., Nierhaus, T., Steinbrink, J., Obrig, H., Wartenburger, I., 2011. Acoustic Processing of Temporally Modulated Sounds in Infants: Evidence from a Combined Near-Infrared Spectroscopy and EEG Study. Front. Psychol. 1, 1-14. https://doi.org/10.3389/fpsyg.2011.00062

Tsuzuki, D., Dan, I., 2014. Spatial registration for functional near-infrared spectroscopy: From channel position on the scalp to cortical location in individual and group analyses. Neuroimage 85, 92-103. https://doi.org/10.1016/j.neuroimage.2013.07.025

Verly, M., Verhoeven, J., Zink, I., Mantini, D., Peeters, R., Deprez, S., Emsell, L., Boets, B., Noens, I., Steyaert, J., Lagae, L., De Cock, P., Rommel, N., Sunaert, S., 2014. Altered functional connectivity of the language network in ASD: Role of classical language areas and cerebellum. NeuroImage Clin. 4, 374-382. https://doi.org/10.1016/j.nicl.2014.01.008

Wallace, G.L., Dudley, K., Anthony, L., Pugliese, C.E., Orionzi, B., Clasen, L., Lee, N.R., Giedd, J.N., Martin, A., Raznahan, A., Kenworthy, L., 2017. Divergence of Age-Related Differences in Social-Communication: Improvements for Typically Developing Youth but Declines for Youth with Autism Spectrum Disorder. J. Autism Dev. Disord. 47, 472479. https://doi.org/10.1007/s10803-016-2972-5

Wijeakumar, S., Spencer, J.P., Bohache, K., Boas, D.A., Magnotta, V.A., 2015. Validating a new methodology for optical probe design and image registration in fNIRS studies. Neuroimage 106, 86-100.

https://doi.org/10.1016/j.neuroimage.2014.11.022

Wilcox, T., Biondi, M., 2015. fNIRS in the developmental sciences. Wiley Interdiscip. Rev. Cogn. Sci. 6, 263-283. https://doi.org/10.1002/wcs.1343

Xiao, T., Xiao, Z., Ke, X., Hong, S., Yang, H., Su, Y., Chu, K., Xiao, X., Shen, J., Liu, Y., 2012. Response Inhibition Impairment in High Functioning Autism and Attention Deficit Hyperactivity Disorder: Evidence from Near-Infrared Spectroscopy Data. PLoS One 7. https://doi.org/10.1371/journal.pone.0046569

Yanagisawa, K., Nakamura, N., Tsunashima, H., Narita, N., 2016. Proposal of auxiliary diagnosis index for autism spectrum disorder using near-infrared spectroscopy. Neurophotonics 3, 31413. https://doi.org/10.1117/1.NPh.3.3.031413

Zhu, H., Fan, Y., Guo, H., Huang, D., He, S., 2014. Reduced interhemispheric functional connectivity of children with autism spectrum disorder: evidence from functional near infrared spectroscopy studies. Biomed. Opt. Express 5, 1262. https://doi.org/10.1364/BOE.5.001262

Zhu, H., Li, J., Fan, Y., Li, X., Huang, D., He, S., 2015. Atypical prefrontal cortical responses to joint/non-joint attention in children with autism spectrum disorder (ASD): A functional near-infrared spectroscopy study. Biomed. Opt. Express 6, 690. https://doi.org/10.1364/BOE.6.000690

Zilbovicius, M., Meresse, I., Chabane, N., Brunelle, F., Samson, Y., Boddaert, N., 2006. Autism, the superior temporal sulcus and social perception. Trends Neurosci. 29, 359-366. https://doi.org/10.1016/j.tins.2006.06.004

Zwaigenbaum, L., Bryson, S.E., Brian, J., Smith, I.M., Roberts, W., Szatmari, P., Roncadin, C., Garon, N., Vaillancourt, T., 
2016. Stability of diagnostic assessment for autism spectrum disorder between 18 and 36 months in a high-risk cohort. Autism Res. 9, 790-800. https://doi.org/10.1002/aur.1585 
Table 1 Characteristics and results of fNIRS studies on functional activation in ASD $^{1}$

\begin{tabular}{|c|c|c|c|c|c|c|c|c|c|c|c|c|}
\hline \multirow[t]{2}{*}{ Study (year) } & \multicolumn{4}{|c|}{ ASD \& High-risk of ASD group } & \multicolumn{2}{|c|}{$\begin{array}{l}\text { Comparison } \\
\text { group }\end{array}$} & \multicolumn{4}{|c|}{ NIRS measurement } & \multirow[t]{2}{*}{ Task \& Stimuli } & \multirow[t]{2}{*}{$\begin{array}{l}\text { Main findings of fNIRS } \\
\text { measurement }\end{array}$} \\
\hline & $\begin{array}{l}\text { Sub- } \\
\text { group }\end{array}$ & $\begin{array}{l}\text { Mean } \\
\text { age } \\
(\mathrm{sd})\end{array}$ & $\begin{array}{c}\mathrm{N} \\
(\mathrm{M} / \mathrm{F})\end{array}$ & $\begin{array}{l}\text { Diagnosis } \\
\text { criteria }\end{array}$ & $\begin{array}{l}\text { Sub- } \\
\text { group }\end{array}$ & $\begin{array}{c}\mathrm{N} \\
(\mathrm{M} / \mathrm{F})\end{array}$ & System & $\begin{array}{l}\text { Wavelength } \\
\text { (nm) }\end{array}$ & $\begin{array}{c}\text { Chann } \\
\text { els }\end{array}$ & $\begin{array}{c}\text { S-D } \\
\text { distance } \\
(\mathrm{cm})\end{array}$ & & \\
\hline
\end{tabular}

\section{Task: Social perception}

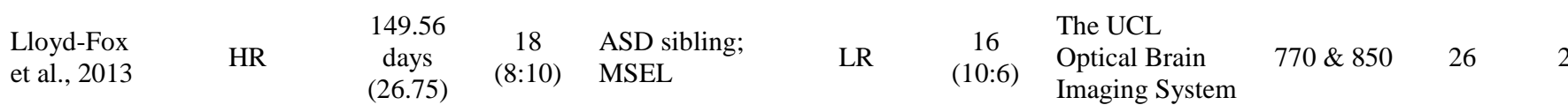

social videos, pictures of transport, vocal and non-vocal sound

social videos pictures of transport, vocal and non-vocal sound

$\begin{array}{cl}16 & \text { Optical Brain } \\ (10: 6) & \text { Imaging System }\end{array}$

$770 \& 850$

26 ADI-R; Vineland-II; MSEL Mullen

months

$(0,58)$
LR

$\begin{array}{cl}13 & \text { The UCL } \\ \text { (4:9) } & \text { Optical Brain } \\ & \text { Imaging System }\end{array}$

social videos and non-social videos, baseline pictures of transport

\begin{tabular}{|c|c|c|c|c|}
\hline $\begin{array}{l}\text { Braukmann } \\
\text { et al., } 2017\end{array}$ & HR & $\begin{array}{c}5.37 \\
\text { months } \\
(0,58)\end{array}$ & $\begin{array}{c}16 \\
(9: 7)\end{array}$ & $\begin{array}{l}\text { ASD sibling; } \\
\text { MSEL }\end{array}$ \\
\hline
\end{tabular}

\section{Task: Face processing}

Jung et al.

2016

ASD

15.6

years

$(9,55)$

$\begin{array}{cl}8 & \text { ADOS; } \\ (8: 0) & \text { GARS-2 }\end{array}$

(8:0) GARS-2

31.6

Nakadoi et

years

(5.0)

$\begin{array}{ll}14 & \text { DSM-IV-TR; } \\ (6: 8) & \text { AQ; }\end{array}$

TDC

$\begin{array}{cl}12 & \text { TechEn, CW6 } \\ & \\ 12: 0) & \\ 14 & \text { Hitachi, ETG- } \\ (6: 8) & 4000\end{array}$

(6:8) 4000
TDC
$690 \& 830$

$\begin{array}{llll}690 \& 830 & 14 & 2.6 & \begin{array}{l}\text { Face pictures of } \\ \text { human and robot }\end{array}\end{array}$

2.6

$695 \& 830$

$24 \quad 3$

HR $<$ LR for visual social and vocal condition: the temporal cortex (STG, MTG)

1. HR-ASD < LR for visual social stimuli: the IFG and pSTS-TPJ;

2. HR-ASD < LR for vocal selective

processing: the left aMTG-STG and pSTSTPJ;

2. Brain response in HR-ASD group at 4-6 months correlated with autism symptoms at 3 years.

$\mathrm{HR}<\mathrm{LR}$ for social dynamic stimuli: the right pSTS-TPJ region

1. TD for human face: the right temporal-

occipital cortex > left; 2. no such difference in ASD

PDD $<$ TDC for fearful faces: the PFC

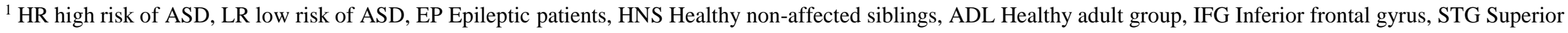

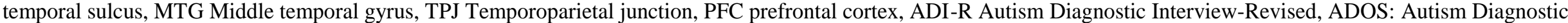

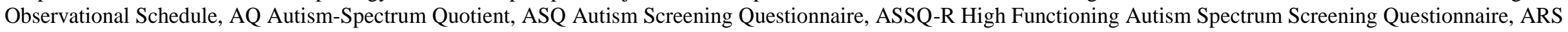

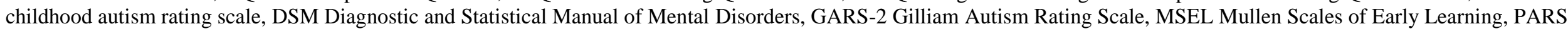
Pervasive Developmental Disorders Autism Society Japan Rating Scale, Vineland-II Vineland Adaptive Behaviour Scale.
} 
Table 1 Characteristics and results of fNIRS studies on functional activation in ASD

\begin{tabular}{|c|c|c|c|c|c|c|c|c|c|c|c|c|}
\hline \multirow[t]{2}{*}{ Study (year) } & \multicolumn{4}{|c|}{ ASD \& High-risk of ASD group } & \multicolumn{2}{|c|}{$\begin{array}{l}\text { Comparison } \\
\text { group }\end{array}$} & \multicolumn{4}{|c|}{ NIRS measurement } & \multirow[t]{2}{*}{ Task \& Stimuli } & \multirow[t]{2}{*}{$\begin{array}{l}\text { Main findings of fNIRS } \\
\text { measurement }\end{array}$} \\
\hline & $\begin{array}{l}\text { Sub- } \\
\text { group }\end{array}$ & $\begin{array}{l}\text { Mean } \\
\text { age } \\
(\mathrm{sd}) \\
\end{array}$ & $\begin{array}{l}\mathrm{N} \\
(\mathrm{M} / \mathrm{F})\end{array}$ & $\begin{array}{l}\text { Diagnosis } \\
\text { criteria }\end{array}$ & $\begin{array}{l}\text { Sub- } \\
\text { group }\end{array}$ & $\begin{array}{l}\mathrm{N} \\
(\mathrm{M} / \mathrm{F})\end{array}$ & System & $\begin{array}{l}\text { Wavelength } \\
(\mathrm{nm})\end{array}$ & $\begin{array}{l}\text { Chann } \\
\text { els }\end{array}$ & $\begin{array}{l}\text { S-D } \\
\text { distance } \\
(\mathrm{cm})\end{array}$ & & \\
\hline
\end{tabular}

Task: Face processing

$\begin{array}{llccl} & \text { Asperge } & & & \\ \text { Kita et al., } & \text { r } & 10.2 & & \\ 2011 & \text { Autism: } & \text { years } & 10 & \text { DSM-IV-TR } \\ & \text { high- } & (1.1) & & \\ & \text { function } & & & \\ & \text { ing } & & & \end{array}$

Fox et al.

2013

HR

Autism:

Mori et al.

2015

\section{high-}

function

ing

Ichikawa et

al., 2014

ASD

ASD+A

DHD

7.06

10

month

ASD sibling

$16 \quad 3$

Liu et al.,
2017

ASD:

high-

function years

2
$(2: 0)$ ADOS- II

ing

\section{Task: Joint attention/ Mental state/ Imitation}

Zhu et al.

$$
\text { Autism }
$$

2015

Asperge

8.75

Kajiume et

al., 2013

PDD
21 DSM-IV-TR

(16:5) AQ

(1.34)

10.7

years
$(2,9)$
6
$(6 \cdot 0) \quad$ DSM-IV
LR

$\begin{array}{lcl}\text { TDC } & (13: 0) & \text { Spectratech, } \\ \& & \& & \text { OEG-16 } \\ \text { ADL } & 11 & \\ & (11: 0) & \end{array}$

$770 \& 840$

TDC

2 Hitachi ETG-

TDC

$\begin{array}{cl}10 & \text { Hitachi, ETG- } \\ (4: 6) & 4000\end{array}$

$695 \& 830$

24

TDC

10
$(10: 0)$

Shimazu,

$780,805 \&$

830

Hitachi ETG-

$$
4000
$$

$695 \& 830$

face

mo

Training task:

house-matching,

face-matching,

and bonus display

Morphing movies

of self-face,

miliar face, an

unfamiliar face

Movie of

mother/stranger

with a neutral or

smiling facial

expression

Emotional facial

expression

ictures of

her's face or

nger's female

Joint attention

eye-moving and

red dot movie

clips

Imitation task:

video of a woman

turning a bottle on and off
1. ADL for self-face recognition: the right IFG > left IFG

2. ADL $>$ ASD and

TDC: the right IFG

3. In ASD group,

significant relationship

between oxy-Hb in

right IFG and ASD

severity and SC score

1. For LR, oxy-Hb in

the frontal and temporal

cortex: mother>strange

2. For HR, deoxy-Hb

in the frontal and

temporal cortex:

mother>stranger

Autism $<$ TDC for the imitation task: the IFG

Children were

classified into Autism

and ADHD group with

a high classification

accuracy: the right TPJ

The participant with

autism who received

real-feedback showed

more behavioral

mprovement during

facial recognition

Autism $<$ TDC for joint attention task: the PFC

PDD $<$ TDC for face

imitation task: the

frontal and premotor cortex 
Table 1 Characteristics and results of fNIRS studies on functional activation in ASD

\begin{tabular}{|c|c|c|c|c|c|c|c|c|c|c|c|c|}
\hline \multirow[t]{2}{*}{ Study (year) } & \multicolumn{4}{|c|}{ ASD \& High-risk of ASD group } & \multicolumn{2}{|c|}{ Comparison group } & \multicolumn{4}{|c|}{ NIRS measurement } & \multirow[t]{2}{*}{ Task \& Stimuli } & \multirow[t]{2}{*}{$\begin{array}{l}\text { Main findings of fNIRS } \\
\text { measurement }\end{array}$} \\
\hline & $\begin{array}{l}\text { Sub- } \\
\text { group }\end{array}$ & $\begin{array}{l}\text { Mean } \\
\text { age } \\
(\mathrm{sd})\end{array}$ & $\begin{array}{c}\mathrm{N} \\
(\mathrm{M} / \mathrm{F})\end{array}$ & $\begin{array}{c}\text { Diagnosis } \\
\text { criteria }\end{array}$ & $\begin{array}{l}\text { Sub- } \\
\text { group }\end{array}$ & $\begin{array}{c}\mathrm{N} \\
(\mathrm{M} / \mathrm{F})\end{array}$ & System & $\begin{array}{l}\text { Wavelength } \\
(\mathrm{nm})\end{array}$ & $\begin{array}{l}\text { Chann } \\
\text { els }\end{array}$ & $\begin{array}{c}\text { S-D } \\
\text { distance } \\
(\mathrm{cm})\end{array}$ & & \\
\hline
\end{tabular}

Task: Joint attention/ Mental state/ Imitation

Iwanaga et

al., 2013

ASD

$\begin{array}{ccl}11,5 & 16 & \text { DSM-IV-TR } \\ \text { years } & (14 \cdot 2) & \text { PARS }\end{array}$

$(1,8)$

ASSQ-R

TDC

16 Hitachi,

(12:4) ETG-4000

$695 \& 830$

\section{Task: Language}

Minagawa-

Kawai et al.,

2009

ASD

9.2

years

(1.8)

9 ASQ

(7:2) Vineland-II

TDC

$\begin{array}{cl}9 & \text { Hitachi, } \\ (7: 2) & \text { ETG 7000 }\end{array}$

ETG 7000

$785 \& 830$

8

Edwards et

al., 2017

\begin{tabular}{|c|c|c|c|}
\hline HR & $\begin{array}{c}3.58 \\
\text { months } \\
(0.39)\end{array}$ & $\begin{array}{c}21 \\
(13: 8)\end{array}$ & ASD siblit \\
\hline
\end{tabular}

LR

17 Hitachi,

(10:7)

ETG-4000

$695 \& 830$

24

TDC

3
$(2: 1)$

Gallagher et

PDD

12 years

(1:0) /

Task: Letter fluency

$\begin{array}{llccl} & & \text { Child: } & \text { Child: } & \\ & \text { Autism, } & 12.7 & 14 & \\ \text { Kawakubo } & \text { Asperge } & (3.4) & (12: 2) & \text { DSM-IV } \\ \text { et al., 2009 } & \text { r \& } & \& & \& & \text { CARS-TV } \\ & \text { PDD- } & \text { Adult: } & \text { Adult: } & \\ & \text { NOS } & 26.7 & 13 & \\ & & (6.1) & (9: 4) & \\ & & & & \\ \begin{array}{l}\text { Kuwabara et } \\ \text { al., 2006 }\end{array} & \text { PDD } & 26.5 & 10 & \text { DSM-IV } \\ & & \begin{array}{c}\text { years } \\ (7,1)\end{array} & (6: 4) & \text { CARS } \\ \end{array}$

fluency task:
Japanese verb

Mental state task:

Pictures of

people's eyes;

Object's

characteristics

task: photographs

of truck\& flowers

ASD $<$ TD for mental

state task: the frontal

cortex

ASD $<$ TDC for

lateralization for

speech: the temporal

cortex/Wernicke's area

1. Female HR> LR

\&Male HR for all trials:

the left and right

anterior temporal

region;

Sounds with

trisyllabic

sequences

Female HR>LR to

the last 4 trials: the

anterior \& posterior

temporal region.

Language task:

verbal fluency;

Motor control

This PDD showed a

clear lateralization in

task: nonsense

syllable repetition

the Broca's area.
Tissue

Child:

TDC 14(12:2)

TDC \&

Unaffect 12(4:8)

Adult:

siblings $13(9: 4)$

\&

12(7:5)

Hamamatsu, $\quad 775,810 \&$

NIRO-200

775,
850

50

Letter

syllable

1. Child group: no significant difference: the PFC

2. Adult group:

ASD $<$ TDC of oxy-Hb

but no deoxy-Hb

1. ASD <TDC: the PFC

2. In PDD, Oxy-Hb was negatively correlated

with the verbal 
Table 1 Characteristics and results of fNIRS studies on functional activation in ASD

\begin{tabular}{|c|c|c|c|c|c|c|c|c|c|c|c|c|}
\hline \multirow[t]{2}{*}{ Study (year) } & \multicolumn{4}{|c|}{ ASD \& High-risk of ASD group } & \multicolumn{2}{|c|}{ Comparison group } & \multicolumn{4}{|c|}{ NIRS measurement } & \multirow[t]{2}{*}{ Task \& Stimuli } & \multirow[t]{2}{*}{$\begin{array}{l}\text { Main findings of fNIRS } \\
\text { measurement }\end{array}$} \\
\hline & $\begin{array}{l}\text { Sub- } \\
\text { group }\end{array}$ & $\begin{array}{l}\text { Mean } \\
\text { age } \\
(\mathrm{sd}) \\
\end{array}$ & $\begin{array}{c}\mathrm{N} \\
(\mathrm{M} / \mathrm{F})\end{array}$ & $\begin{array}{l}\text { Diagnosis } \\
\text { criteria }\end{array}$ & $\begin{array}{l}\text { Sub- } \\
\text { group }\end{array}$ & $\begin{array}{c}\mathrm{N} \\
(\mathrm{M} / \mathrm{F})\end{array}$ & System & $\begin{array}{l}\text { Wavelength } \\
\text { (nm) }\end{array}$ & $\begin{array}{l}\text { Chann } \\
\text { els }\end{array}$ & $\begin{array}{c}\text { S-D } \\
\text { distance } \\
(\mathrm{cm})\end{array}$ & & \\
\hline \multicolumn{13}{|c|}{ Task: Letter fluency } \\
\hline $\begin{array}{l}\text { Iwanami et } \\
\text { al., } 2011\end{array}$ & $\begin{array}{l}\text { Asperge } \\
\mathrm{r}\end{array}$ & $\begin{array}{l}27.2 \\
\text { years } \\
(8.5)\end{array}$ & $\begin{array}{c}20 \\
(14: 6)\end{array}$ & $\begin{array}{l}\text { DSM-IV } \\
\text { AQ }\end{array}$ & TDC & $\begin{array}{c}18 \\
(12: 6)\end{array}$ & $\begin{array}{l}\text { Hitachi, } \\
\text { ETG-4000 }\end{array}$ & $695 \& 830$ & 52 & 3 & $\begin{array}{l}\text { Category \& letter } \\
\text { fluency tasks }\end{array}$ & $\begin{array}{l}\text { Asperger<TDC for the } \\
\text { letter fluency task: the } \\
\text { PFC }\end{array}$ \\
\hline $\begin{array}{l}\text { Narita et al., } \\
2012\end{array}$ & ASD & $\begin{array}{c}29.5 \\
\text { years }\end{array}$ & $\begin{array}{c}11 \\
(3: 8)\end{array}$ & $\begin{array}{l}\text { DSM-IV } \\
\text { ADI-R }\end{array}$ & TDC & $\begin{array}{c}22 \\
(6: 16)\end{array}$ & $\begin{array}{l}\text { Hamamatsu, } \\
\text { NIRO-201 }\end{array}$ & $\begin{array}{l}735,810 \& \\
850\end{array}$ & 2 & 3 & $\begin{array}{l}\text { Task-switching: } \\
\text { geometrical } \\
\text { figures } \\
\text { with different } \\
\text { color and shapes }\end{array}$ & $\begin{array}{l}\text { Autism subjects did not } \\
\text { show clear response } \\
\text { and right laterality } \\
\text { during the working- } \\
\text { memory task: the PFC } \\
\text { ASD subjects showed }\end{array}$ \\
\hline Narita, 2015 & ASD & $\begin{array}{c}20 \text { years } \\
(4.76)\end{array}$ & $\begin{array}{c}4 \\
(4: 0)\end{array}$ & $\begin{array}{l}\text { DSM-5 } \\
\text { ADI-R }\end{array}$ & I & l & $\begin{array}{l}\text { Hamamatsu, } \\
\text { PocketNIRS }\end{array}$ & $\begin{array}{l}735,810 \& \\
850\end{array}$ & 2 & 3 & $\begin{array}{l}\text { NFB training \& } \\
\text { working memory } \\
\text { switching task }\end{array}$ & $\begin{array}{l}\text { improved activation in } \\
\text { the PFC and relevant } \\
\text { tasks performance } \\
\text { during neurofeedback } \\
\text { training. }\end{array}$ \\
\hline $\begin{array}{l}\text { Yanagisawa } \\
\text { et al., } 2016\end{array}$ & $\begin{array}{l}\text { Asperge } \\
\text { r \& } \\
\text { Autism: } \\
\text { high- } \\
\text { function } \\
\text { ing }\end{array}$ & $\begin{array}{c}29.5 \\
\text { years }\end{array}$ & $\begin{array}{c}11 \\
(3: 8)\end{array}$ & $\begin{array}{l}\text { DSM-IV } \\
\text { ADI-R }\end{array}$ & TDC & $\begin{array}{c}21 \\
(5: 16)\end{array}$ & $\begin{array}{l}\text { Hamamatsu, } \\
\text { NIRO-200 }\end{array}$ & $\begin{array}{l}775,810 \& \\
850\end{array}$ & 2 & 3 & $\begin{array}{l}\text { Working memory } \\
\text { task: graphics } \\
\text { with different } \\
\text { color and shapes }\end{array}$ & $\begin{array}{l}\text { Autism< TDC of } \\
\text { weighted separability } \\
\text { values: the left } \\
\text { dorsolateral PFC. }\end{array}$ \\
\hline \multicolumn{13}{|c|}{ Task: Response inhibition } \\
\hline $\begin{array}{l}\text { Funabiki et } \\
\text { al., } 2012\end{array}$ & $\begin{array}{l}\text { Asperge } \\
\text { r \& } \\
\text { PDD- } \\
\text { NOS }\end{array}$ & $\begin{array}{c}16.8 \\
\text { years } \\
(6.1)\end{array}$ & $\begin{array}{c}11 \\
(10: 1)\end{array}$ & DSM-IV-TR & TDC & $\begin{array}{c}12 \\
(10: 2)\end{array}$ & $\begin{array}{l}\text { Shimazu, } \\
\text { OMM-3000 }\end{array}$ & $\begin{array}{l}780,805 \& \\
830\end{array}$ & 32 & 3 & $\begin{array}{l}\text { Listening \& } \\
\text { Ignoring task: } \\
\text { sounds of tones } \\
\text { and meaningful } \\
\text { stories }\end{array}$ & $\begin{array}{l}\text { Autism subjects } \\
\text { showed different } \\
\text { patterns of activation: } \\
\text { the PFC }\end{array}$ \\
\hline $\begin{array}{l}\text { Ishii- } \\
\text { Takahashi et } \\
\text { al., } 2014\end{array}$ & $\begin{array}{l}\text { Asperge } \\
\text { r \& } \\
\text { PDD- } \\
\text { NOS }\end{array}$ & $\begin{array}{l}30.8 \\
\text { years } \\
(7.2)\end{array}$ & $\begin{array}{c}21 \\
(8: 13)\end{array}$ & $\begin{array}{l}\text { DSM-IV } \\
\text { ADI-R } \\
\text { ADOS } \\
\text { AQ }\end{array}$ & $\begin{array}{l}\text { TDC } \\
\& \\
\text { ADHD }\end{array}$ & $\begin{array}{c}21 \\
(13: 8) \\
\& \\
19 \\
(11: 8)\end{array}$ & $\begin{array}{l}\text { Hitachi } \\
\text { ETG-4000 }\end{array}$ & $695 \& 830$ & 52 & 3 & $\begin{array}{l}\text { Pre- and post- } \\
\text { periods: an image } \\
\text { of a dog; Stop } \\
\text { signal task: "GO" } \\
\text { and "Stop" sound } \\
\text { Go/No-go task: }\end{array}$ & $\begin{array}{l}\text { 1. ASD<TDC for the } \\
\text { stop task: in the PFC } \\
\text { 2. ASD<AHDH: the } \\
\text { PFC }\end{array}$ \\
\hline
\end{tabular}


Table 2 Characteristics and results of fNIRS studies on functional connectivity in ASD

\begin{tabular}{|c|c|c|c|c|c|c|c|c|c|c|c|c|}
\hline \multirow[t]{2}{*}{ Study (year) } & \multicolumn{4}{|c|}{ ASD \& High-risk of ASD group } & \multicolumn{2}{|c|}{ Comparison group } & \multicolumn{4}{|c|}{ NIRS measurement } & \multirow[t]{2}{*}{ Task \& Stimuli } & \multirow[t]{2}{*}{$\begin{array}{l}\text { Main findings of fNIRS } \\
\text { measurement }\end{array}$} \\
\hline & $\begin{array}{l}\text { Sub- } \\
\text { group }\end{array}$ & $\begin{array}{l}\text { Mean } \\
\text { age } \\
(\mathrm{sd})\end{array}$ & $\begin{array}{c}\mathrm{N} \\
(\mathrm{M} / \mathrm{F})\end{array}$ & $\begin{array}{l}\text { Diagnosis } \\
\text { criteria }\end{array}$ & $\begin{array}{l}\text { Sub- } \\
\text { group }\end{array}$ & $\begin{array}{c}\mathrm{N} \\
(\mathrm{M} / \mathrm{F})\end{array}$ & System & $\begin{array}{l}\text { Wavelength } \\
\text { (nm) }\end{array}$ & $\begin{array}{c}\text { Chann } \\
\text { els }\end{array}$ & $\begin{array}{c}\text { S-D } \\
\text { distance } \\
(\mathrm{cm})\end{array}$ & & \\
\hline $\begin{array}{l}\text { Keehn et al., } \\
2013\end{array}$ & HR & $\begin{array}{c}3,6,9 \\
\& 12 \\
\text { months }\end{array}$ & 33 & ASD sibling & LR & 43 & $\begin{array}{l}\text { Hitachi, } \\
\text { ETG-4000 }\end{array}$ & $695 \& 830$ & 24 & 3 & $\begin{array}{l}\text { Trisyllabic } \\
\text { sequences "ABB" } \\
\text { or "ABC" }\end{array}$ & $\begin{array}{l}\text { For the functional } \\
\text { connectivity between } \\
\text { frontal and temporal } \\
\text { cortex: } \\
1 . \mathrm{HR}>\mathrm{LR} \text { at } 3 \text { months } \\
\text { 2. HR<LR at } 12 \text { months }\end{array}$ \\
\hline $\begin{array}{l}\text { Kikuchi et } \\
\text { al., } 2013\end{array}$ & $\begin{array}{l}\text { Asperge } \\
\text { r, } \\
\text { Autism } \\
\& \\
\text { atypical } \\
\text { Autism }\end{array}$ & $\begin{array}{l}47-86 \\
\text { months }\end{array}$ & $\begin{array}{c}15 \\
(13: 2)\end{array}$ & $\begin{array}{l}\text { DSM-IV } \\
\text { ADOS } \\
\text { DISCO }\end{array}$ & TDC & $\begin{array}{c}15 \\
(13: 2)\end{array}$ & $\begin{array}{l}\text { Shimadzu's, } \\
\text { FOIRE- } \\
3000\end{array}$ & $\begin{array}{l}780,805 \& \\
830\end{array}$ & 2 & 3 & $\begin{array}{l}\text { Stimulation-free } \\
\& \text { attractive } \\
\text { picture-card }\end{array}$ & $\begin{array}{l}\text { 1. ASD }>\text { TDC for } \\
\text { bilateral PFC } \\
\text { connectivity } \\
\text { 2. In ASD group, } \\
\text { higher bilateral PFC } \\
\text { connectivity is related } \\
\text { to lower social ability }\end{array}$ \\
\hline $\begin{array}{l}\text { J. Li et al., } \\
2016\end{array}$ & ASD & $\begin{array}{l}9.3 \\
\text { years } \\
(1.4)\end{array}$ & $\begin{array}{c}25 \\
(18: 7)\end{array}$ & DSM-IV-TR & TDC & $22(18: 4)$ & $\begin{array}{l}\text { Shimadzu's, } \\
\text { FOIRE- } \\
3000\end{array}$ & $\begin{array}{l}780,805 \& \\
830\end{array}$ & 24 & 3 & Stimulation-free & $\begin{array}{l}\text { ASD<TDC: functional } \\
\text { connectivity between } \\
\text { bilateral temporal lobe }\end{array}$ \\
\hline $\begin{array}{l}\text { Y. Li et al., } \\
2016\end{array}$ & ASD & $\begin{array}{c}6.1 \\
\text { years } \\
(1.1)\end{array}$ & $\begin{array}{c}12 \\
(9: 3)\end{array}$ & $\begin{array}{l}\text { Diagnosed by } \\
\text { hospital }\end{array}$ & TDC & $\begin{array}{c}12 \\
(9: 3)\end{array}$ & $\begin{array}{l}\text { Shimadzu, } \\
\text { LABNIRS }\end{array}$ & $\begin{array}{l}780,805 \& \\
830\end{array}$ & 44 & 3 & Stimulation-free & $\begin{array}{l}\text { ASD } \angle \text { TDC for lobe- } \\
\text { level inter-region } \\
\text { connectivity in the right } \\
\text { PFC. }\end{array}$ \\
\hline
\end{tabular}


Supplementary Figure 1: Risk of bias assessment.

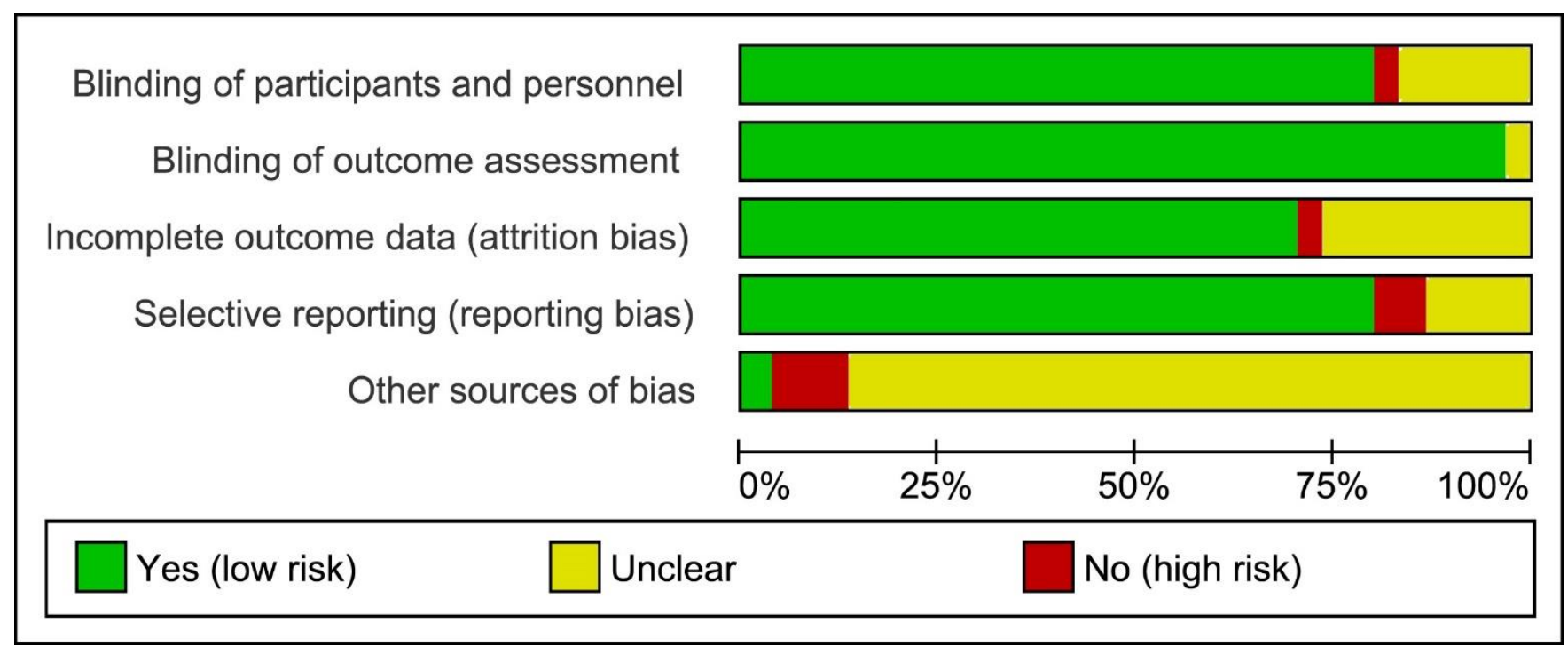

